Type of the Paper: Article

\title{
Isolation of skeletal muscle-derived cells modeling Neural Crest-derived Stem Cells for Therapeutic Use in Regenerative Periodontology
}

\author{
Grimm W.-D.1,2,5, 9, N. Didenko5, K. Dhingra7, A. Dolgalev5 , N. Enukashvily,4, T. Fritsch5,6,8, B. \\ Giesenhagen $^{5,10}$, D. Ivolgin ${ }^{3}$ and M.A. Vukovic ${ }^{5,9}$ \\ W.-D. Grimm, Periodontology, ${ }^{1}$ University of Witten/Herdecke, Witten, Germany \\ W.-D. Grimm, N. Enukashvily, ${ }^{2}$ Cell Technology Lab, North Western State Medical University, St. \\ Petersburg, Russian Federation \\ D. Ivolgin, ${ }^{3}$ Pokrovsky Stem Cell Bank, St. Petersburg, Russian Federation \\ N. Enukashvily, ${ }^{4}$ Institute of Cytology, Russian Academy of Science, St. Petersburg, Russian Federation \\ W.-D. Grimm, N. Didenko, A. Dolgalev, T. Fritsch, B. Giesenhagen, M.A. Vukovic, ${ }^{5}$ Center for Innovation \\ and Technology Transfer, Stavropol State Medical University, Stavropol, Russian Federation \\ T. Fritsch, ${ }^{6}$ Dental Department, State Medical Sechenov University, Moscow, Russian Federation \\ K. Dhingra, ${ }^{7}$ Division of Periodontics, Centre for Dental Education and Research, All India Institute of \\ Medical Sciences, New Delhi, India. \\ T. Fritsch, ${ }^{8}$ NAM-clinics, Bayerisch Gmain, Germany \\ W.-D. Grimm, M.A. Vukovic, ${ }^{9}$ Praxisteam Haßlinghausen, Sprockhövel, Germany \\ B. Giesenhagen, ${ }^{10}$ Implantology Center, Kassel, Germany
}

\begin{abstract}
Periodontitis is microbial infection affecting periodontium, the tooth supporting structure and affects $>743$ million people worldwide. Neural crest-derived stem cells (NCSCs) hold the promise to regenerate the damaged periodontium. These cells have been identified within adult adipose tissue, periodontal ligament, and palatal tissue. Typical enzymatic isolation protocols are expensive, time consuming and often not clinically compliant. Enzyme-free, mechanical dissociation has been suggested as an alternative method of generating cell suspensions required for cell separation and subsequent expansion ex vivo. In our study, samples of rat skeletal muscle tissue were used to appraise the suitability of a novel mincing method of mechanical dissociation against enzymatic digestion with collagenase and dispase. Skeletal muscle is readily available and has been shown to contain NCSC populations. We used a Rigenera-Human Brain Wave ${ }^{\circledR}$ prototype mincer to produce a suspension of skeletal muscle-derived cells modeling NCSCs. We have compared the resulting cell cultures produced via mechanical dissociation and enzymatic dissociation, producing single cell suspensions suitable for Magnetic Cell Sorting (MACs) and Fluorescence-activated cell sorting (FACS). Despite the Countess Automated Cytometry data demonstrating that cell suspensions produced by mechanical dissociation $(\mathrm{n}=24)$ contain on average 26.8 times as many viable cells as enzymatic cell suspensions $(n=18)$, enzymatic suspensions produced more successful cell cultures. Spheroids and subsequently adherent cells formed from 4 enzymatic cell suspensions (44.4\%) vs. 1 mechanical cell suspension (8.3\%). Enzymatic digestion protocols formed spheroids faster and more plentifully than mechanical cell suspensions. Adherent cells and spheroids isolated via both methods appear morphologically similarly to NCSCs from our previous studies.
\end{abstract}

Running title: Isolation of skeletal muscle-derived cells modeling Neural Crest-derived Stem Cells

Keywords: Isolation; skeletal muscle-derived cells, Neural Crest-derived Stem Cells; Mechanical Dissociation; Regenerative Periodontology; Enzymatic Digestion 


\section{Introduction}

Periodontitis is a chronic multifactorial inflammatory disease associated with dysbiotic plaque biofilms and characterized by progressive destruction of the tooth-supporting apparatus ${ }^{1}$. In 2010, severe periodontitis was identified as the world's 6th most prevalent disease, affecting more than 743 million people ${ }^{2}$. The need for an effective treatment is further highlighted by the fact that periodontitis remains the leading cause of tooth loss worldwide ${ }^{3}$. Tooth loss via exfoliation or professional extraction is witnessed in advanced cases of periodontitis following extensive attachment loss and resorption of alveolar bone. Most current treatments for patients suffering from periodontitis focus on the conservation of remaining periodontal structures and reducing disease progression ${ }^{4}$. Despite continuing development and research into treatments for periodontitis, including tissue engineering and regenerative therapies, difficulty remains in restoring all the damaged structures of the periodontium ${ }^{5}$. Furthermore, even with current treatments, studies have shown worldwide prevalence of severe periodontitis stagnated between the years of 1990 and 20172.

Periodontal ligament (PDL) cells are resident cells of the periodontium and have a critical role in tissue homeostasis, destruction, and regeneration by their ability to synthesize and degrade collagen and other matrix molecules ${ }^{6}$. The immune response is orchestrated by numerous cytokines, chemokines, and growth factors, which are produced by resident host cells. However, these cells can also participate in the immunoinflammatory processes of periodontitis 78 . Periodontal healing is determined by the type of cells that repopulate the root. By the application of regenerative treatment methods, which promote PDL cell proliferation, migration and attachment, the re-establishment of the initial periodontal tissue architecture is possible ${ }^{9}$. However, the outcomes of currently available regenerative treatment approaches are sometimes compromised by several factors and are not predictable ${ }^{10,11}$. Therefore, the search for new therapeutic methods with a regenerative potential are a major goal in periodontology ${ }^{12}$.

Stem cells represent an exciting potential therapy for periodontitis thanks to their ability to differentiate into many different cell types, such as bone and connective tissues ${ }^{13}$. However, the appropriate type of stem cells must be selected to develop the most effective treatment for periodontitis. In 2004, the periodontal ligament was identified as a source of highly proliferative, multipotent mesenchymal stem cells with potential for the treatment of periodontitis ${ }^{14}$. Conversely to mesenchymal PDL-SCs which differentiate into those cells and tissues related to the mesenchyme; neural crest cells (NCSCs) have displayed multipotent capabilities to differentiate into derivatives of both mesenchymal and neuronal lineage ${ }^{15}$. The most attractive sources for adult NCSC isolation are dental sources because of easy access and minimally invasive biopsy. NCSCs have been identified and isolated from several tissues and organs of mammals at later fetal and postnatal stages of development ${ }^{16}$. Adult NCSCs could undergo directed differentiation into adipocytes, osteoblasts, chondrocytes, melanocytes, neurons, and Schwann cells 17,$18 ; 15$. Moreover, adult cultured NCSC therapeutic application led to the restoration of bone ${ }^{19}$, cartilage defects ${ }^{20}$, damaged peripheral nerves ${ }^{21}$, and spinal cord ${ }^{22}$. Therefore, selective isolation of adult oral NCSCs are important technical issues for the successful applications for regenerative medicine purposes. Various techniques were applied for the selective isolation of adult NCSCs:

- fluorescence-activated cell sorting 23,24

- selective culturing conditions for growth as shown as neurosphere-like structures ${ }^{25}$

- explant technique ${ }^{26}$

Only pluripotent stem cells exceed the cellular plasticity displayed by isolated adult multipotent neural crest-derived stem cells (NC-SCs). The hard palate presents as an accessible source of craniofacial tissue for the procurement of neural crest-related cells ${ }^{25}$. In 2009, populations of multipotent NC-SCs were identified within the ridges of the hard palate of adult Wistar rats ${ }^{27}$. Considering the highly regenerative nature of the hard palate and accessibility of palatal rugae, this procedure could act as a minimally invasive source of proliferative, therapeutically appropriate multipotent NC-SCs ${ }^{25}$. Following isolation and cultivation of nestin-positive and Sox2-positive NC-SCs, secondary neurosphere forming assays identified NC-SCs forming spheres at a frequency of $1.8 \%$, compared to a frequency of $0.01 \%$ in PDL-SCs ${ }^{27,28}$. The NC-SCs are a heterogeneous population of stem/stromal cells 
isolated from subepithelial palatal tissue complex. Administration of NC-SCs holds a strong therapeutic potential for regenerative and wound healing medicine applications aimed at functional restoration of tissues damaged by chronic periodontal diseases ${ }^{29}$. NC-SCs are obtained from subepithelial palatal tissue complex by collagenase digestion, incubation/isolation, and pelletized by centrifugation. Enzymatic disaggregation may alter the relevant biological characteristics of subepithelial palatal tissue complex, while providing release of complex, multi-attachment of cell-tocell and cell-to-matrix, effectively eliminating the bioactive ECM and periadventitial attachments. The isolation of cellular elements is considered as a minimal-invasive access in periodontal surgery ${ }^{30,17}$. Several alternative, nonenzymatic methods of palatal tissue processing have been developed to obtain via minimal mechanical manipulation an autologous NC-SC product intended for delivery, reducing the procedure duration, decreasing regulatory burden, and shortening the translation into the clinical setting ${ }^{26}$. Ideally, these procedures might allow for the integration of harvesting and processing of palatal tissue for ease of transferring, in a single procedure utilizing a nonexpanded cellular product at the point of periodontal regeneration, while permitting intraoperative autologous NC cellular-based periodontal regenerative therapies. Therefore, palatalderived NC-SCs present as more potent and more proliferative alternative to PDL-SCs. Here, we investigate the options, advantages, and limitations of the methods alternative to enzymatic processing currently developed for minimal manipulation of palatal tissue.

In order to liberate stem cells from tissue samples, the tissue must be dissociated using mechanical or enzymatic methods. In the reports mentioned previously, samples of periodontal ligament and palatal rugae were dissociated using enzymatic methods, involving treatments with enzymes such as trypsin, dispase, and collagenase I and II ${ }^{14,31,27,25}$. The limitations of enzymatic digestion surround the facts that these enzymes are both expensive, and often not "xeno-free" 32 . Enzymes sourced from different species of animals, or bacteria could result in serious adverse reactions for the patient, including infection or anaphylaxis ${ }^{32}$. Furthermore, inconsistencies with enzyme concentration, purity and activity have been noted between different bathes and manufacturers. These issues stem from the common production method of enzymes via recombinant bacteria ${ }^{33}$, requiring adaptation of digestion protocols depending on varying $\mathrm{w} / \mathrm{v} \%$ concentrations of available enzymes. Mechanical dissociation aims to provide an alternative, enzyme- and xeno-free process for the liberation of stem cells from tissue samples. Methods utilizing centrifugal force, vibration, pressure, shearing force, and radiation force have been developed to replace the requirement of an enzymatic digestion step. However, these methods have displayed varying successes ${ }^{33,34}$.

This study aimed to compare dissociation of mammalian tissue achieved via novel mechanical mincing techniques against conventional enzymatic dissociation methods utilizing dispase I and collagenase I. This is a proof of principle study, which as a model for palatal-derived NC-SCs compares the mechanical isolation of skeletal muscle-derived cells with enzymatic methods. Muscle tissue samples taken from rats were selected to assess the differences in cell suspensions produced by these mechanical and enzymatic dissociation methods. Recently, Mellows et al. and Mitchell et al. 2019 reported that the secretome from human amniotic fluid stem cells (AFSCs) facilitates tissue regeneration in a cardiotoxin (CTX)-induced model of muscle degeneration 28,35 . In accordance with these publications rat skeletal muscle contain a variety of different cells displaying the characteristics of mesenchymal stem cells. Hence, rat skeletal muscle presents as a suitable, readily available sample tissue for the initial assessment of a novel mechanical dissociation protocol against proven enzymatic digestion methods. The research hypothesis for this study was that clinically viable skeletal muscle-derived cells modeling NC-derived stem cells can be isolated from samples of mammalian tissue using mechanical mincing techniques, instead of enzymatic digestion for the treatment of periodontitis.

\section{Materials and Methods:}

\subsection{Rat muscle tissue sample:}


Fresh samples of rat muscle tissue specifically, samples of the fibularis, tibialis and extensors were isolated the day before scheduled experiments. A beaker of Male Wistar Kyoto (WKY, 8-12 weeks, 200-300 g) rats were killed according to schedule one of the Animals (Scientific Procedures) Act 1986 and thus was given an ethical approval waiver by the University of Reading Animal Welfare and Ethical Review Board (AWERB). Tissue samples in Krebs solution was provided, stored at a temperature of approximately $4^{\circ} \mathrm{C}$.

\subsection{Cell Medium:}

Rat smooth muscle cells were cultured in high glucose DMEM supplemented with 20\% FBS, $1 \%$ L-glutamine and additionally with 1\% Penicillin-Streptomycin (Sigma-Aldrich, Germany), 77\% Dulbecco's Modified Eagle's Medium - High Glucose (Sigma-Aldrich, Germany), 0.00005\% FGF and $1 \%$ Amphotericin B. Unless otherwise stated, cell cultures were fed every 3 days. Successful cultures in T25 flasks would have two additions of $3 \mathrm{ml}$ of media for the first two 3-day cycles, before supernatant was removed and adherent cells were split.

\subsection{Weighing Tissue Samples:}

Tissue sample mass was measured using a digital precision balance (Sartorius, R200D Digital Analytical Lab Balance) in grams, providing accuracy to five decimal places, facilitating recording in milligrams. The mass of each sample was maintained within a 10\% range between lightest to heaviest, for each set of samples for each experiment. Before treatment with either mechanical or enzymatic dissociation methods, tissue samples were manually minced into divisions of 6,12 , or 18 (Figure 1). Once manually minced, tissue samples were gently rinsed in 1\% Penicillin-Streptomycin in PBS solution, comprising of Dulbecco's PBS (Modified, without calcium chloride and magnesium chloride) (Sigma-Aldrich, Germany) and Penicillin- Streptomycin (Sigma-Aldrich, Germany) in order to minimize microbial contamination during dissociation procedures.

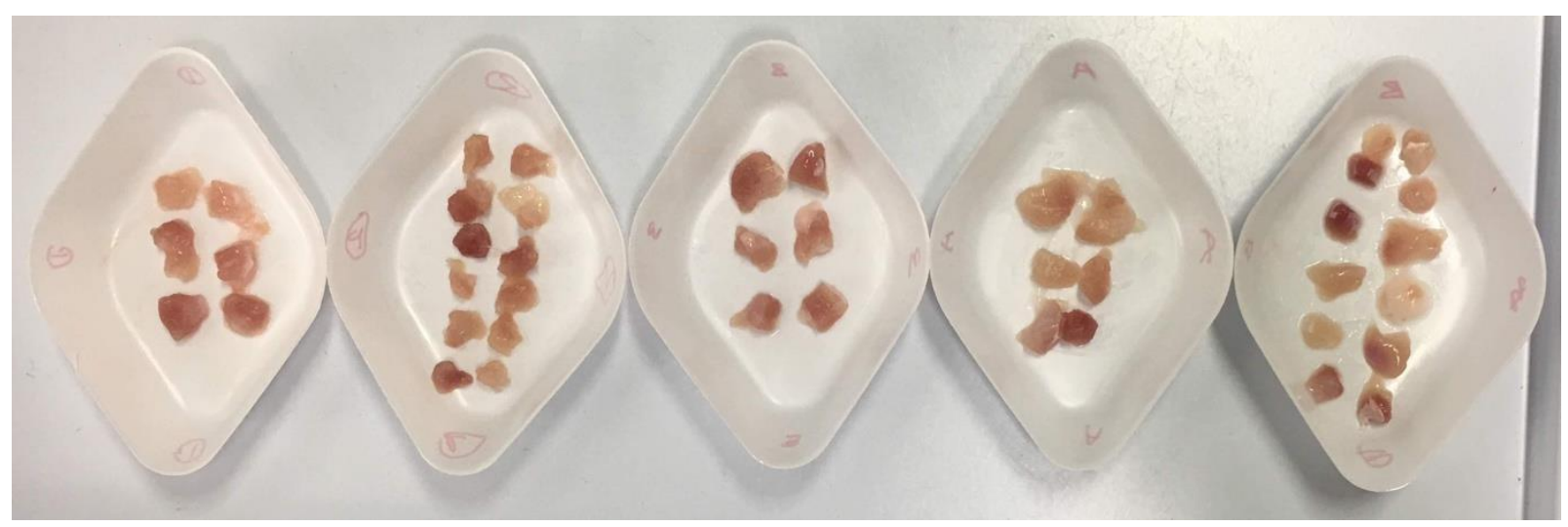

Figure 1. Manually minced rat muscle tissue prior to enzymatic and mechanical dissociation.

\subsection{Enzymatic Digestion Methods:}

Following manual mincing and washing, a select cohort of rat tissue samples were subject to enzymatic dissociation. Firstly, tissue samples were treated with $2 \mathrm{ml}$ of $1 \mathrm{U} / 2 \mathrm{ml}$ Dispase I in PBS solution, comprising of $10 \mu \mathrm{l}$ of $200 \mathrm{U} / \mathrm{ml}$ Dispase I protease (Sigma-Aldrich, Germany) with $1990 \mu \mathrm{l}$ sterile Dulbecco's PBS (Sigma-Aldrich, lot no. Germany). The tissue sample in Dispase-PBS solution were vortexed together in a $10 \mathrm{ml}$ falcon tube for 30 seconds and refrigerated for 24-hours at a temperature of $4^{\circ} \mathrm{C}$; completing the first stage of the dissociation procedure. Following 24-hours of refrigeration, samples were centrifuged at 300G for 10 minutes (Eppendorf, Centrifuge 5810R) to create a pellet, so that the Dispase-PBS supernatant could be removed. The resultant pellet was then re-suspended in $2 \mathrm{ml}$ of a $1 \mathrm{U} / 2 \mathrm{ml}$ Collagenase I in PBS solution, comprising of $200 \mu \mathrm{l} 5 \mathrm{U} / \mathrm{ml}$ Collagenase I (Collagenase from Clostridium histolyticum) (Sigma-Aldrich, Germany) with $1800 \mu \mathrm{l}$ 
sterile Dulbecco's PBS (Modified, without calcium chloride and magnesium chloride) (SigmaAldrich, Germany). The resultant tissue in Collagenase-PBS suspension was incubated in a water bath at $37.5^{\circ} \mathrm{C}$ for 90 minutes. Following incubation, the suspension was made up to $12 \mathrm{ml}$ with sterile Dulbecco's PBS and transferred to a $50 \mathrm{ml}$ falcon tube. Once transferred, the suspension was filtered using a $70 \mu \mathrm{m}$ cell strainer into a $10 \mathrm{ml}$ falcon tube to remove any debris. The resultant suspension was centrifuged at $300 \mathrm{G}$ for 10 minutes (Eppendorf, Centrifuge 5810R) to create a pellet so the collagenasePBS supernatant can be removed. The resultant pellet was re-suspended in $1 \mathrm{ml}$ of media, containing 20\% Foetal Bovine Serum (Sigma-Aldrich, Germany) 1\% L-Glutamine (Sigma-Aldrich, Germany), 1\% Penicillin-Streptomycin (Sigma-Aldrich, Germany) 78\% Dulbecco's Modified Eagle's Medium - High Glucose (Sigma-Aldrich, Germany) and 0.00005\% FGF before counting and seeding.

\subsection{Mechanical Dissociation:}

Following manual mincing and washing, samples selected for mechanical dissociation were stored in 2ml PBS (Sigma-Aldrich, Germany) with 1\% Penicillin-Streptomycin (Sigma-Aldrich, Germany) whilst waiting for mechanical mincing. The prototype mincer provided by was utilized for the mincing of rat muscle samples (Figure 2). Tissue samples were placed into the Rigenera Cons (Rigenera-HBW, 2018) mincing pot with approximately 5ml PBS (Sigma-Aldrich, Germany) and secured with laboratory grade Parafilm M. Mincing was carried out in sessions of 5-10 minutes followed by removal of supernatant via a sterile syringe with the supplied filter. Filtrate was dispensed into a $10 \mathrm{ml}$ falcon tube, and replacement PBS was instilled into the Rigenera Cons device, and re-secured with Parafilm M. An additional 5-10 minutes of mincing was carried out, and the resultant supernatant removed and instilled into the filtrate $10 \mathrm{ml}$ falcon tube. The filtrate solution was made up to $12 \mathrm{ml}$ with sterile Dulbecco's PBS and transferred to a $50 \mathrm{ml}$ falcon tube. Once transferred, the solution was filtered using a $70 \mu \mathrm{m}$ cell strainer into a $15 \mathrm{ml}$ falcon tube to remove any debris. The resultant solution was centrifuged at 300G for 10 minutes to create a pellet so the PBS supernatant can be removed. The resultant pellet was resuspended in $1 \mathrm{ml}$ of media, containing $20 \%$ Foetal Bovine Serum (Sigma-Aldrich, Germany) 1\% L-Glutamine (Sigma-Aldrich, Germany), 1\% Penicillin-Streptomycin (Sigma-Aldrich, Germany) 78\% Dulbecco's Modified Eagle's Medium - High Glucose (Sigma-Aldrich, Germany) and $0.00005 \%$ FGF before counting and seeding.
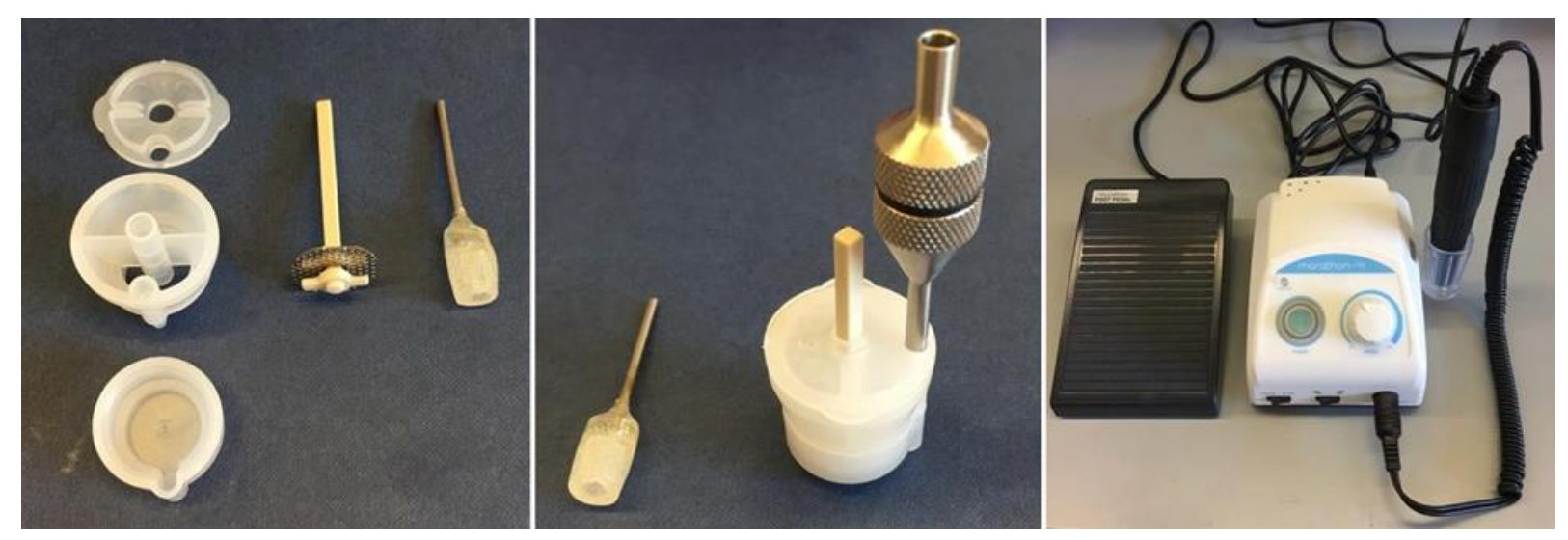

Figure 2. Prototype Mincing Apparatus for Mechanical Dissociation Experiments. (L and M) Rigenera Cons mincing apparatus. (M) Rigenera Cons together with supplied filter. (R) Handheld motor component of the prototype mincing apparatus, including foot pedal control.

\subsection{Cell Population Counts:}

Cell counts for enzymatic and mechanical dissociation were carried out before seeding, using the Countess II FL Automated Cell Counter. $10 \mu \mathrm{l}$ of the $1 \mathrm{ml}$ cell suspension in culture medium was sampled and placed into a 50 $\mu$ l Eppendorf microcentrifuge tube. $10 \mu \mathrm{l}$ of Trypan Blue cell stain was then added to the $10 \mu \mathrm{l}$ cell suspension sample, creating a total volume of $20 \mu \mathrm{l} .10 \mu \mathrm{l}$ of this $20 \mu \mathrm{l}$ 
Trypan Blue-cell suspension was removed from the $50 \mu 1$ Eppendorf microcentrifuge tube and instilled into each chamber of a sterile countess cell counting chamber slide. Each end of the slide can then be inserted into the automated hemocytometer, providing multiple readings for each dissociation experiment.

\subsection{Passaging Cultures:}

Following assessment of confluence using transmitted light microscopy, cell cultures at approximately $80 \%$ confluency were "passaged", or split, in the sterile environment of the laminar flow cabinet. For cell cultures with adherent cells: old cell culture media was removed from the flask using a sterile stripette and disposed of using Biocleanse solution. For cell cultures with suspended cells: old cell culture media was removed from the flask using a sterile stripette and transferred into a $10 \mathrm{ml}$ falcon tube. This cell suspension was centrifuged at $300 \mathrm{G}$ for 10 minutes to create a pellet suitable for resuspension. After removing old cell culture media, the pellet was resuspended in $1 \mathrm{ml}$ fresh media, ready for a cell count or seeding in a new cell culture flask.

The remaining adherent cells and flask were washed with Dulbecco's PBS (Modified, without calcium chloride and magnesium chloride) (Sigma-Aldrich, Germany) in sterile conditions 2-3 times, before the addition of Trypsin-EDTA Solution (Sigma-Aldrich, Germany). $4 \mathrm{ml}$ trypsin was used for a T75 flask, whereas $1.3 \mathrm{ml}$ was used for a T25 flask. Trypsin was distributed over the base of the flask, ensuring all adherent cells are covered. Cell cultures were then incubated for 5 minutes in a $10 \% \mathrm{CO}_{2}$ humidified incubator, at $37^{\circ} \mathrm{C}$. Following incubation, cells were viewed using transmitted light microscopy to assess whether all adherent cells were now detached from the base of the culture flask; additional incubation was applied if gently tapping the side container did not dislodge the remaining adherent cells. A volume of standard cell media, equal to that of the added trypsin solution, was added to the flask using a stripette in the sterile environment of the laminar flow cabinet. The suspended cells present in the trypsin-media solution was centrifuged at $300 \mathrm{G}$ for 10 minutes to create a pellet, so that the trypsin-media supernatant could be removed. Following removal of supernatant, the pellet of cells was resuspended in $1 \mathrm{ml}$ of media, ready for a cell count or for reseeding in a T25 or T75 cell culture flask, with additional fresh media.

\subsection{Transmitted Light Microscopy:}

Invitrogen ${ }^{\mathrm{TM}}$ EVOS $^{\mathrm{TM}} \mathrm{XL}$ microscopes were used to assess cell cultures under transmitted light microscopy. Together with an optical magnification of 10-times, imaging of cell cultures was carried out at 4-, 10-, 20- and 40-times objectives.

\subsection{DAPI/Phalloidin Staining and Microscopy:}

Cells were seeded into an adherent 24-well plate prior to the assay with $1 \mathrm{ml}$ standard cell media. Once cells had adhered, media was removed and replaced with $1 \mathrm{ml}$ of $4 \%$ paraformaldehyde solution for 20 minutes at room temperature. After 20 minutes, paraformaldehyde solution was removed, and the cells washed with PBS three times, at 5-minute intervals. Finally, $150 \mu \mathrm{l}$ of $0.1 \%$ Triton $^{\mathrm{TM}} \mathrm{X}-100$ (Sigma-Aldrich, Germany) in PBS was added to permeabilize adherent cells and left to set at room temperature for half- an-hour and then removed using a pipette. Residual Triton X-100 solution was washed away with three PBS washes, at 5-minute intervals. Each well of cells selected for DAPI/Phalloidin staining were then treated with $250 \mu 1$ of $1 \%$ phalloidin, $99 \%$ DAPI treatment stain solution. The 24 -well plate was subsequently protected from light using foil and refrigerated at $4^{\circ} \mathrm{C}$ overnight. Invitrogen ${ }^{\mathrm{TM}}$ EVOS $^{\mathrm{TM}} \mathrm{FL}$ microscopes were used to assess cell cultures following DAPI/Phalloidin staining protocols using fluorescent light microscopy.

\subsection{Live/Dead Staining and Microscopy:}

Cells were seeded into an adherent 24 -well plate prior to the assay with $1 \mathrm{ml}$ standard cell media. Once cells had adhered, media was removed and replaced with $1 \mathrm{ml}$ of Calcein AM (CalAM) and ethidium homodimer-1 (EthD-1) staining solution. This solution was made by combining $10 \mathrm{ml}$ of 
standard growth media with $20 \mu \mathrm{l}$ of EthD-1 and $5 \mu \mathrm{l}$ of CalAM. Once desired wells have been treated with the EthD-1 and CalAM stain, the plate was incubated for 40 minutes before imaging. Invitrogen ${ }^{\mathrm{TM}}$ EVOS $^{\mathrm{TM}}$ FL microscopes were used to assess cell cultures following live/dead staining protocols using fluorescent light microscopy.

\subsection{Cleaning Protocol:}

The "Rigenera Cons" mincing apparatus was cleaned using a novel cleaning method. Firstly, the mincer was stored in ethanol $70 \% \mathrm{v} / \mathrm{v}$ overnight. Following this, the ethanol was drained off and replaced with a $10 \% \mathrm{w} / \mathrm{v}$ detergent solution of 'Tergazyme' enzyme activated detergent with distilled water in a $150 \mathrm{ml}$ beaker into which the apparatus that needed to be cleaned was placed. Tergazyme $10 \%$ solution was added until all contents of the beaker were completely submerged. The beaker was then secured on a see-saw rocker (Stuart, SSL4) at a rate of 40 oscillations-per-minute for 2 hours. Finally, Tergazyme $10 \% \mathrm{w} / \mathrm{v}$ solution was drained off and a series of washes were carried out using water, double distilled water and finally $70 \% \mathrm{v} / \mathrm{v}$ ethanol.

\subsection{Fibroblasts and Assessment of Cleaning Protocol:}

Adult Human Dermal Fibroblasts (NHDF-Ad) passages 8, 9 and 10 were used to assess the Rigenera Cons cleaning protocol. Control fibroblasts were seeded into a T25 adherent cell culture flask at a cell density of $8.75 \times 10^{4}$ cells in $3 \mathrm{ml}$ of standard cell culture medium. Test fibroblasts were passed through the Rigenera Cons mincing device multiple times using a sterile micropipette within a sterile laminar flow cabinet. Following five minutes of exposure, cells were removed and seeded at a density of $8.75 \times 10^{4}$ cells in $3 \mathrm{ml}$. This process was repeated three times.

\section{Statistical Analysis:}

GraphPad Prism 8 software was utilized for statistical analysis, including Student's t-test, twotailed, with confidence level $95 \%$. P $<0.05$ was used as the definition of statistical significance.

\section{Results:}

4.1. More cells are liberated from tissue samples using mechanical dissociation compared to enzymatic digestion:

Analysis of the cell suspensions produced by mechanical and enzymatic protocols indicates mechanical dissociation as producing significantly larger populations of living cells in comparison to enzymatic digestion (Figure 3).

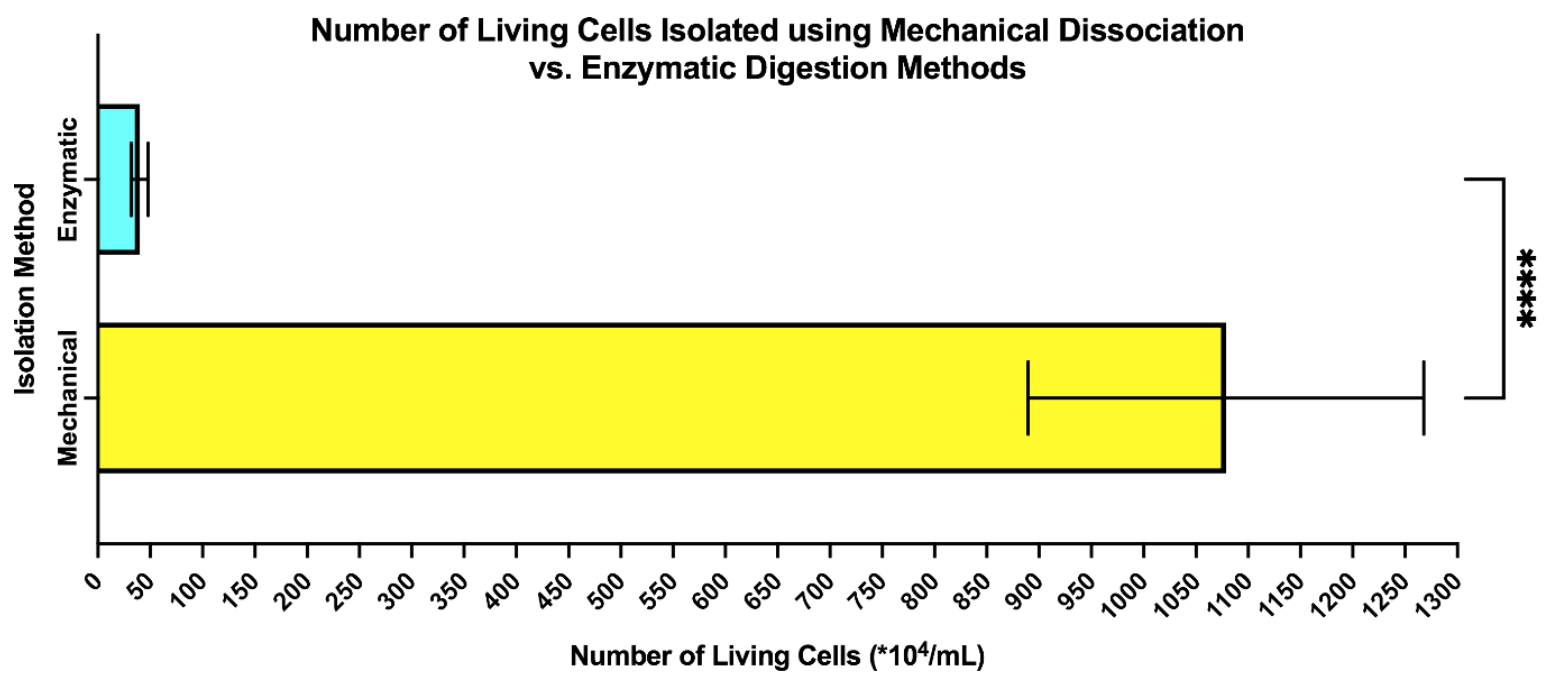


Figure 3. Quantification of the Living Cell Numbers Reveals Higher Yield of Mechanical Dissociation. These cell numbers were quantified using the Countess Automated Cytometer. Data represented as mean and SEM. Student's t-test analysis set at $(\mathrm{P}<0.05)$ indicates extreme statistical significance $(\mathrm{P}<0.0001)$. Enzymatic $\mathrm{n}=18$, Mechanical $\mathrm{n}=24$.

This difference in populations of liberated live cells is despite equal masses of sample tissue used with each technique (Figure 4 ).

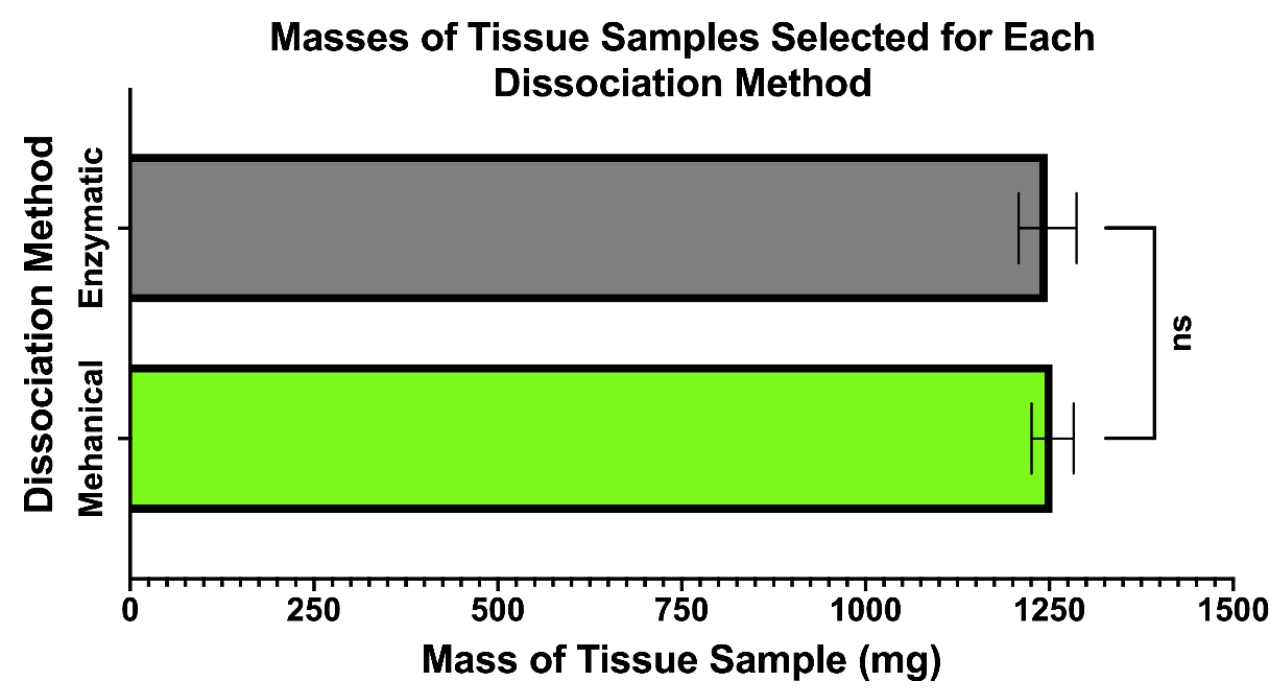

Figure 4. Tissue Samples Selected for Mechanical and Enzymatic Dissociation were of Equal Mass. Data represented as mean and standard error of the mean (SEM). Analysis of tissue sample masses using Student's t-test analysis set at $(\mathrm{P}<0.05)$ indicates no statistical significance between masses of tissue samples selected for each dissociation method. Enzymatic n=9, mechanical n=12.

Figures 5 and 6 further illustrate the differences between populations of living and dead cells present in cell suspensions produced by enzymatic and mechanical dissociative techniques.

Using data from the Countess Automated Cytometer, on an average, enzymatic digestion produced cell suspensions with $89.07 \%$ of cells identified as "alive", compared to $99.64 \%$ of liberated cells identified as "alive" from mechanical dissociation experiments. Considering mean data for sample masses and cell suspension populations, further calculations can identify the average numbers of living cells liberated from $1000 \mathrm{mg}$ of tissue sample, using each dissociative protocol.

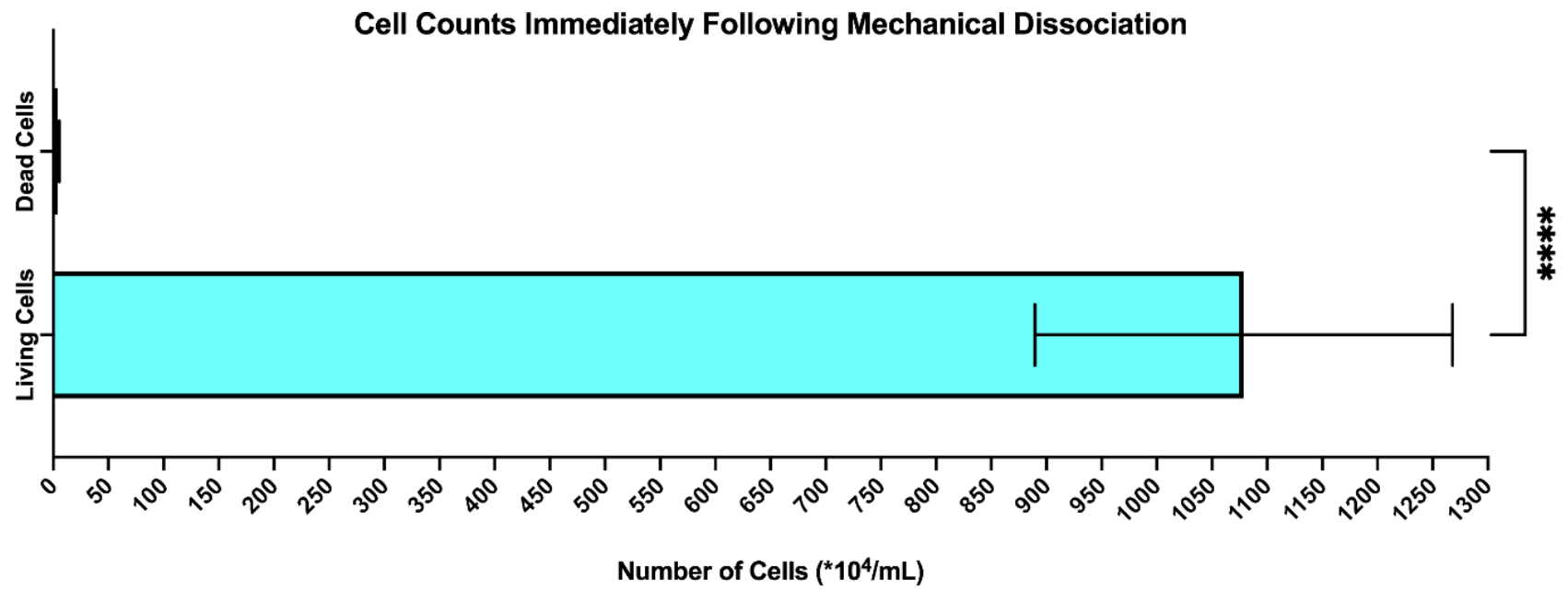

Figure 5. Comparison of living cell and dead cell populations immediately following mechanical dissociation shows on average $99.64 \%$ of cells are alive. These cell numbers were quantified using the 
Countess Automated Cytometer. Data represented as mean and SEM. Student's t-test analysis set at $(\mathrm{P}<0.05)$ indicates extreme statistical significance $(\mathrm{P}<0.0001)$. Mean values for dead cells $=$ $3.934 \times 10^{4} / \mathrm{ml}$ and mean values for living cells $=1079 \times 10^{4} / \mathrm{ml}$. Living Cells $\mathrm{n}=24$, Dead Cells $\mathrm{n}=24$.

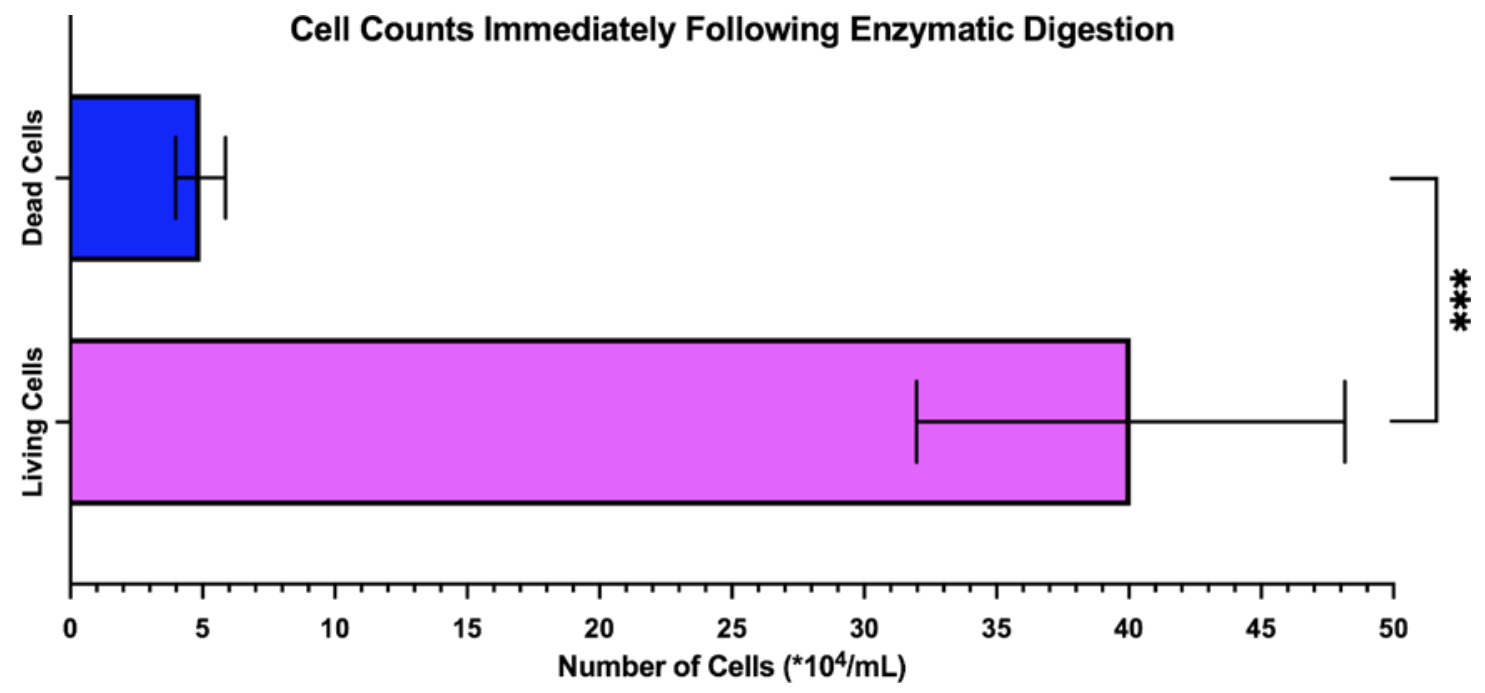

FIG. 6: Comparison of living cell and dead cell populations immediately following enzymatic digestion shows on average $89.07 \%$ of cells are alive. These cell numbers were quantified using the Countess Automated Cytometer. Data represented as mean and SEM. Student's t-test analysis set at $(\mathrm{P}<0.05)$ indicates extreme statistical significance $(0.0001<\mathrm{P}<0.001)$. Mean values for dead cells $=$ $4.919 \times 10^{4} / \mathrm{ml}$ and mean values for living cells $=40.07 \times 10^{4} / \mathrm{ml}$. Living Cells n= 18, Dead Cells n=18.

Data in Table 1 suggests that mechanical dissociation should produce 26.8 times the number of living cells compared to enzymatically produced cell suspensions, using the same mass of tissue sample.

Table 1. Average number of living cells liberated using mechanical or enzymatic protocols per $1000 \mathrm{mg}$ of tissue sample.

\begin{tabular}{cccc}
\hline $\begin{array}{c}\text { Dissociation } \\
\text { Method }\end{array}$ & $\begin{array}{c}\text { Average } \\
\text { Sample Size }\end{array}$ & $\begin{array}{c}\text { Average living } \\
\text { cell population }\end{array}$ & $\begin{array}{c}\text { Average number of } \\
\text { cells per 1000mg tissue } \\
\text { sample }\end{array}$ \\
\hline $\begin{array}{c}\text { Mechanical } \\
\text { Dissociation } \\
\text { Enzymatic } \\
\text { Digestion }\end{array}$ & $1254 \mathrm{mg}$ & $1079 \times 10^{4}$ & $860.45 \times 10^{4}$ \\
\hline
\end{tabular}


Figure 7 shows the visual differences between cell suspensions produced by mechanical and enzymatic protocols. Images 1 and 2 clearly show a typical fine layer of occlusive debris produced by mechanical mincing, compared to the clearer cell suspensions produced by enzymatic digestion (images A and B). Furthermore, suspensions produced from enzymatic digestion (images A and B) included presence of larger fragments of muscle tissue, absent from suspensions produced by mechanical dissociation (images 1 and 2).

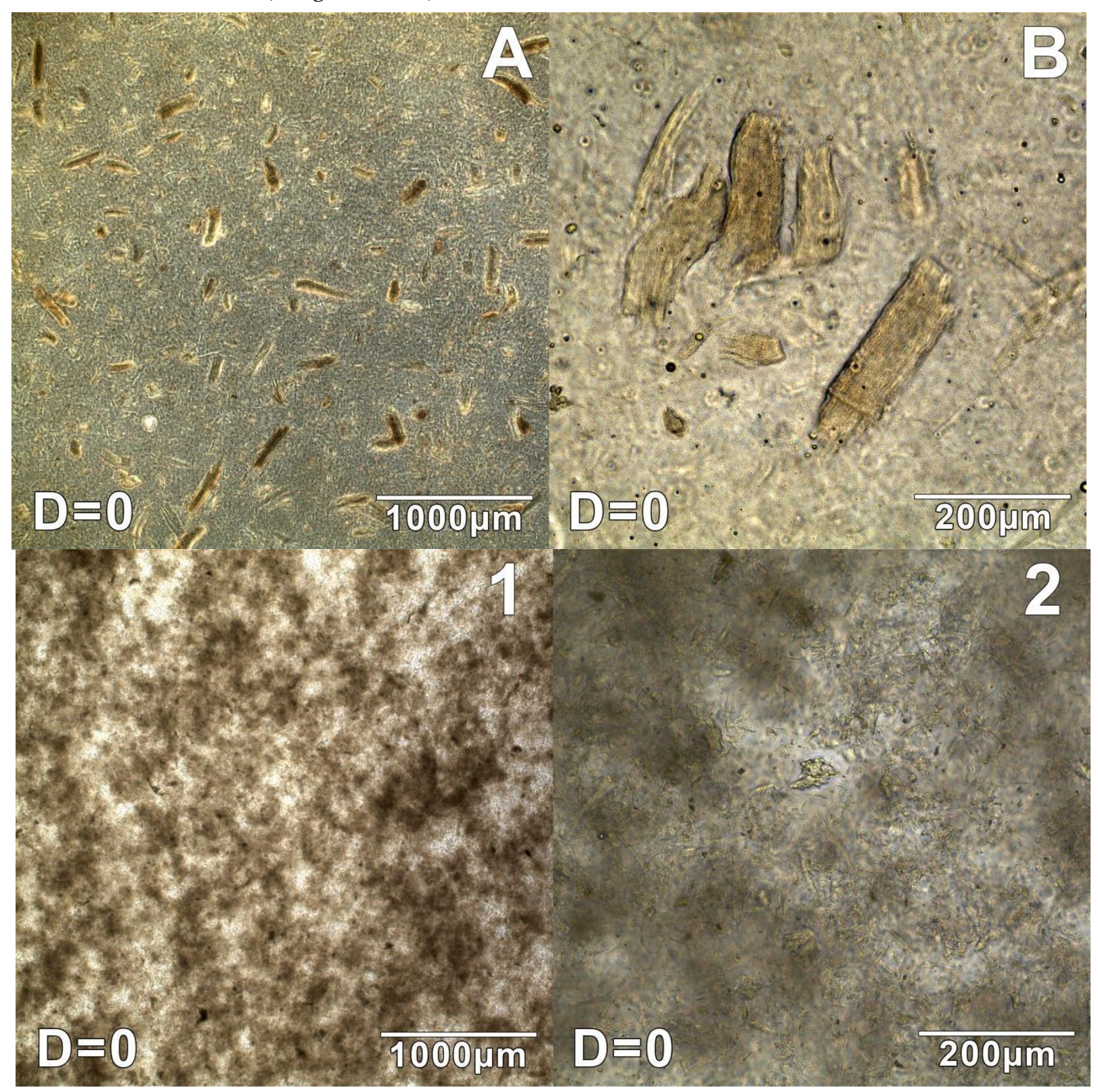

Figure 7. Comparison of cell suspensions immediately after seeding cell suspensions produced by mechanical and enzymatic dissociation techniques shows debris from mincing process. (A and B) Successful culture ‘Enzymatic Dissociation B'. (1 and 2) Successful culture 'Mechanical Dissociation $2^{\prime}$

\subsection{Adhesion of cells following mechanical dissociation and enzymatic digestion:}

Mechanical dissociation and enzymatic digestion successfully produced cultures of adherent cells. Formation of large cellular spheroids, similar in morphology to neurospheres produced by neural crest-derived stem cells, occurred quickly in enzymatic cultures (Figure 8). Successful mechanical cultures produced far fewer numbers of spheroids than seen in enzymatic cultures. Those spheroids that did occur were much smaller and sparsely distributed throughout the flask (images 
A, D and E, Figure 9). Successful mechanical cultures did not reach comparable densities of adhesive cells seen in enzymatic cultures $(D=13)$ until day 19.

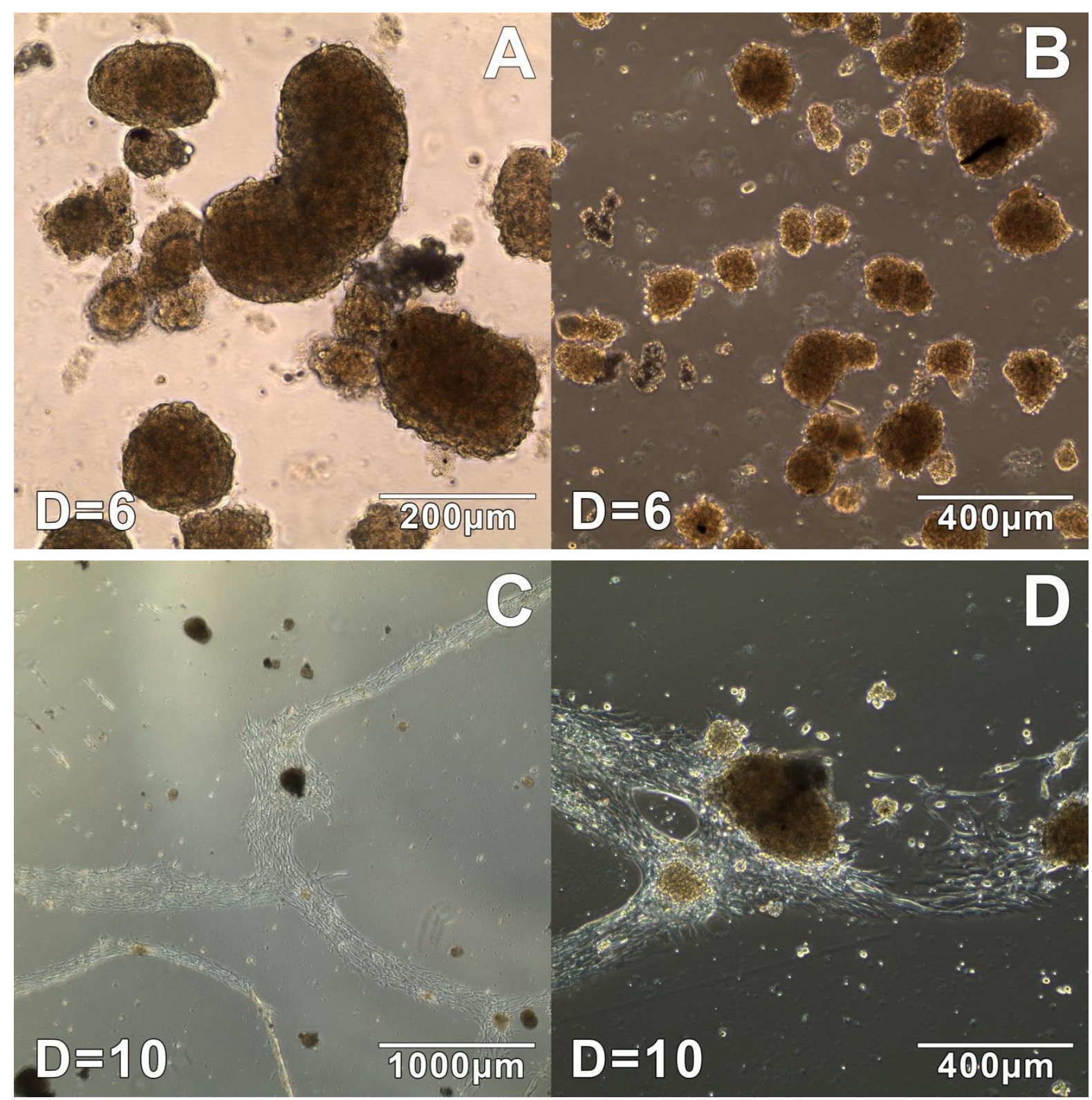



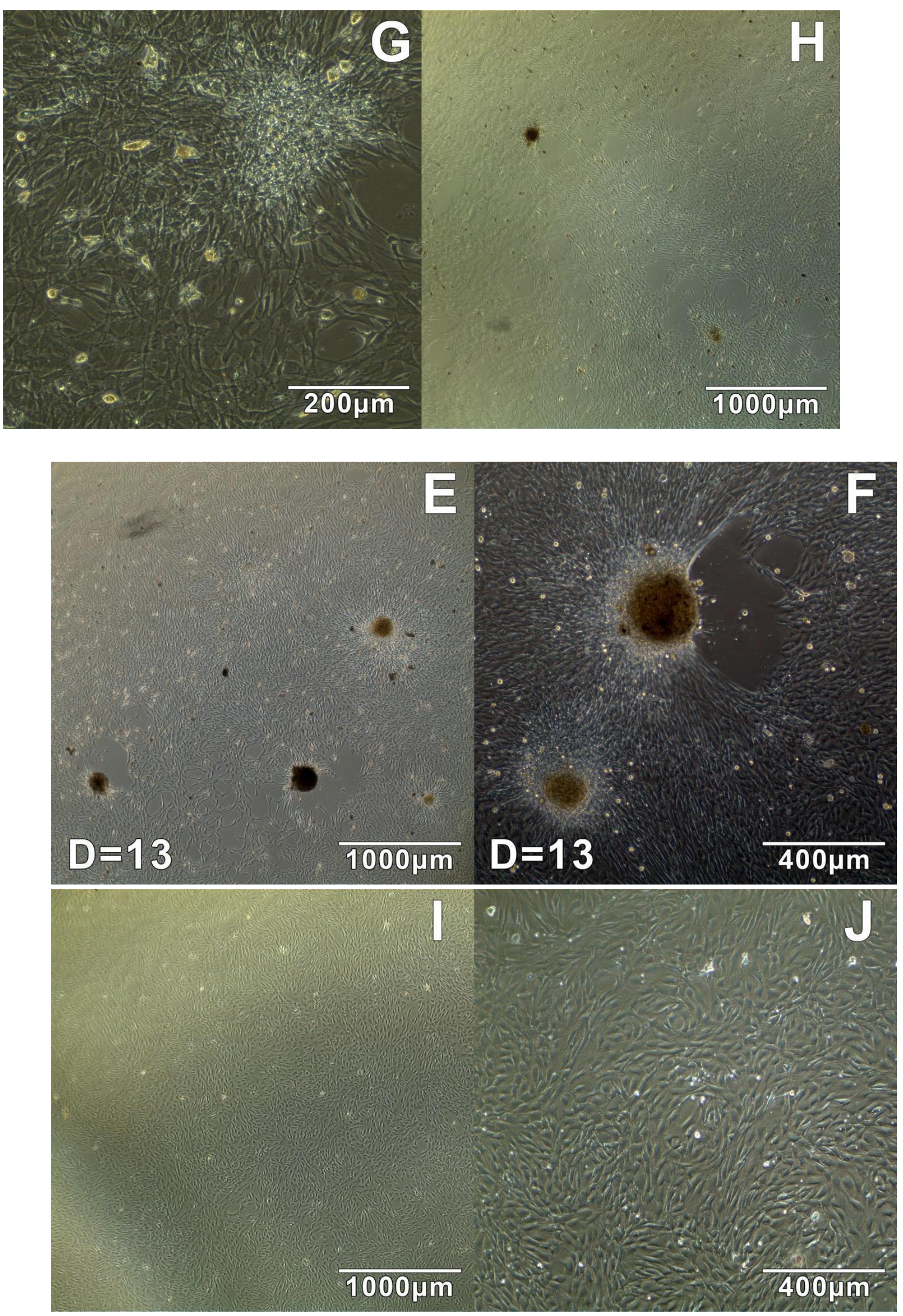
Figure 8. Enzymatic dissociation methods successfully produce spheres, from which adherent cells migrate outwards. (A and B) Multiple cell spheroids, similar in morphology to NCC neurospheres, identified in cell culture 6 days $(D=6)$ after initial cell seed on 13/11/18. (C and D) Migration of adherent cells out of spheres. (E and F) Proliferation of adherent cells, following migration out of cell spheres. Images taken prior to first split, following treatment with Amphotericin B on 23/11/18. ( $G$ and $H$ ) Adherent cell continue to proliferate following first split and Amphotericin B intervention (I and J) Adherent cell continue to proliferate in the absence of spheres, following second split of cell culture 


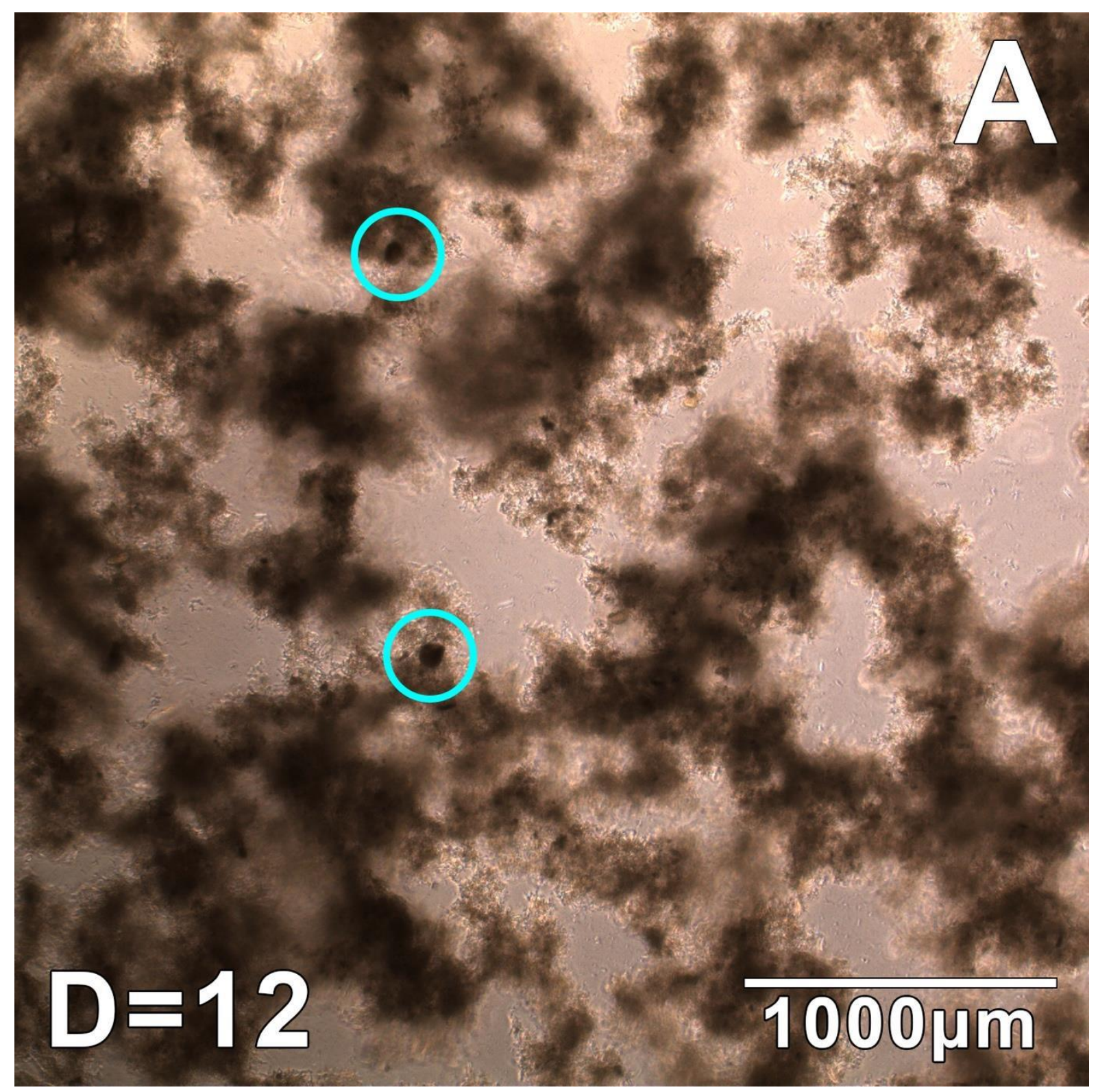



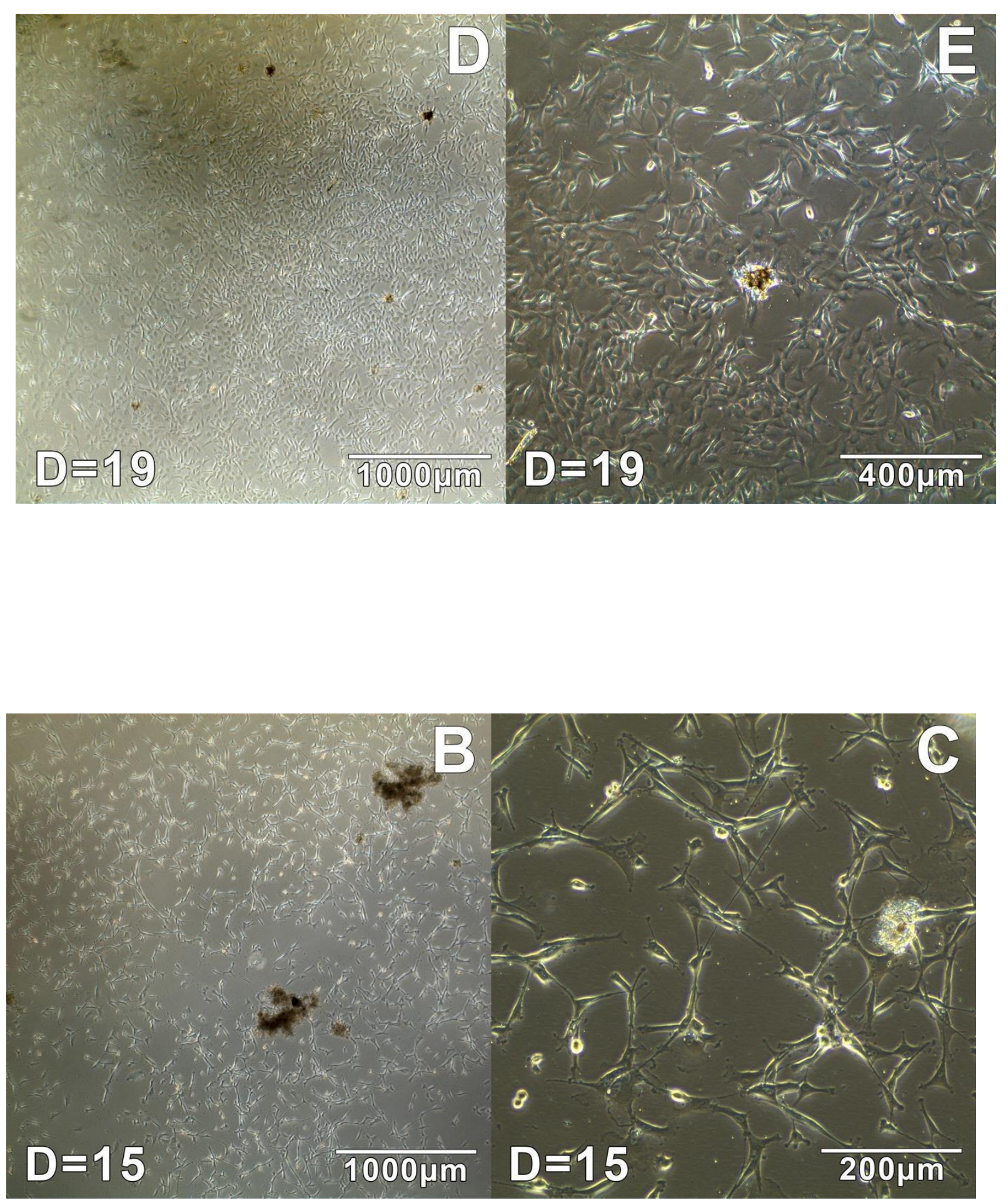


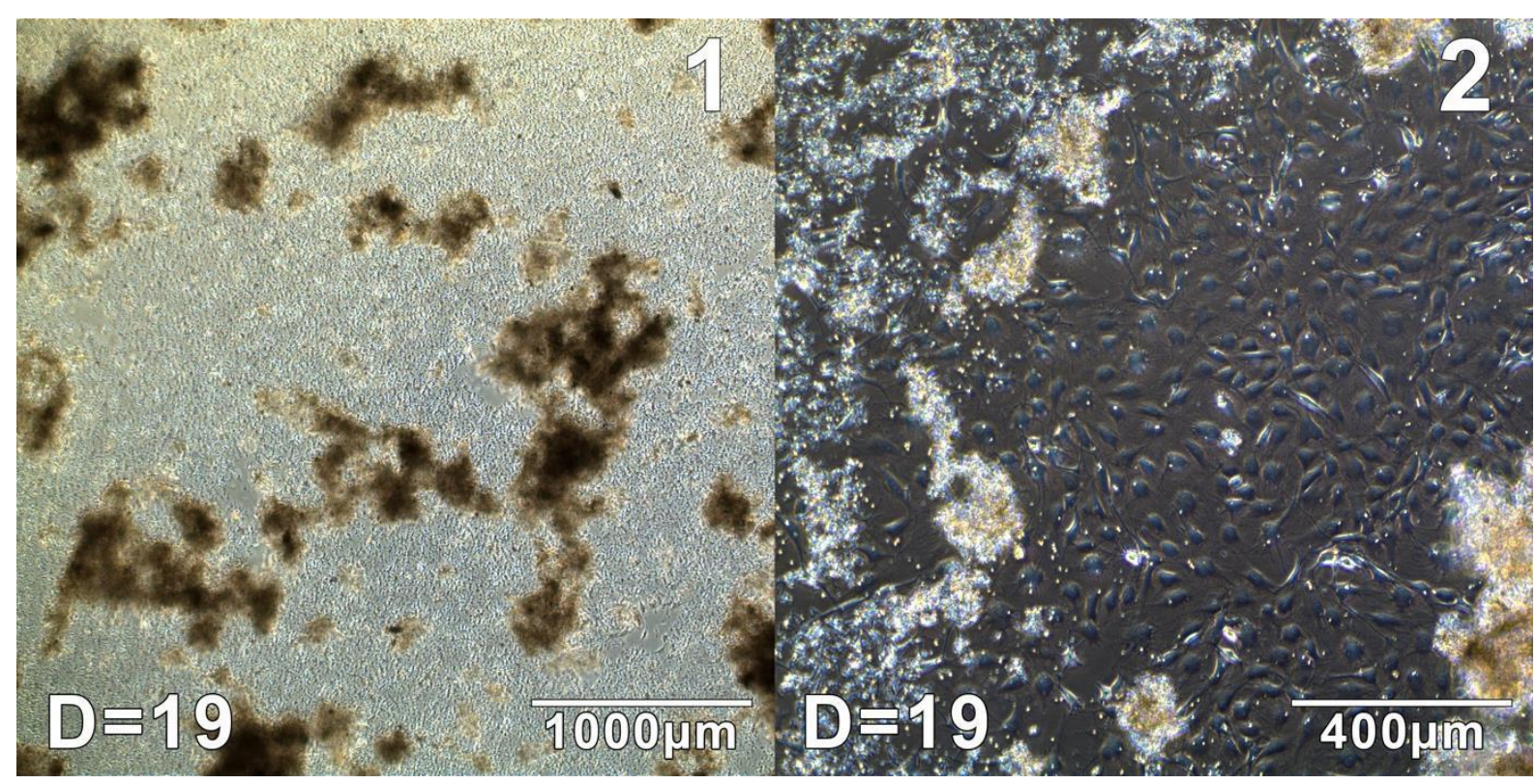

Figure 9. Mechanical Dissociation Methods Displays Similar Capability to Produce Spheres, from which Adherent Cells Migrate Outwards. Possible spheroids identified within tissue sample debris following mechanical dissociation 12 days before $(D=12)$, ( $B$ and $C$ ) Adherent cells identified 15 days after initial seed; following removal of supernatant (1 and 2), (D and E) Adherent cells continue to proliferate following three cycles of media changes/addition. (1 and 2) Supernatant and non-adherent tissue debris produced proliferative cultures of adherent cells when seeded; 19 days after initial isolation.

Both successful mechanical and enzymatic cultures produced adherent cells that responded well to splitting via typical trypsinization methods. Two cell proliferation assays were carried out over a 7-day course to assess the cell proliferation of adherent cells isolated via enzymatic dissociation methods. Over 7 days with no addition of fresh media, cell populations grew from populations of approximately 10,000 cells per well to an average of 71,300 cells per well (Fig. 10). 

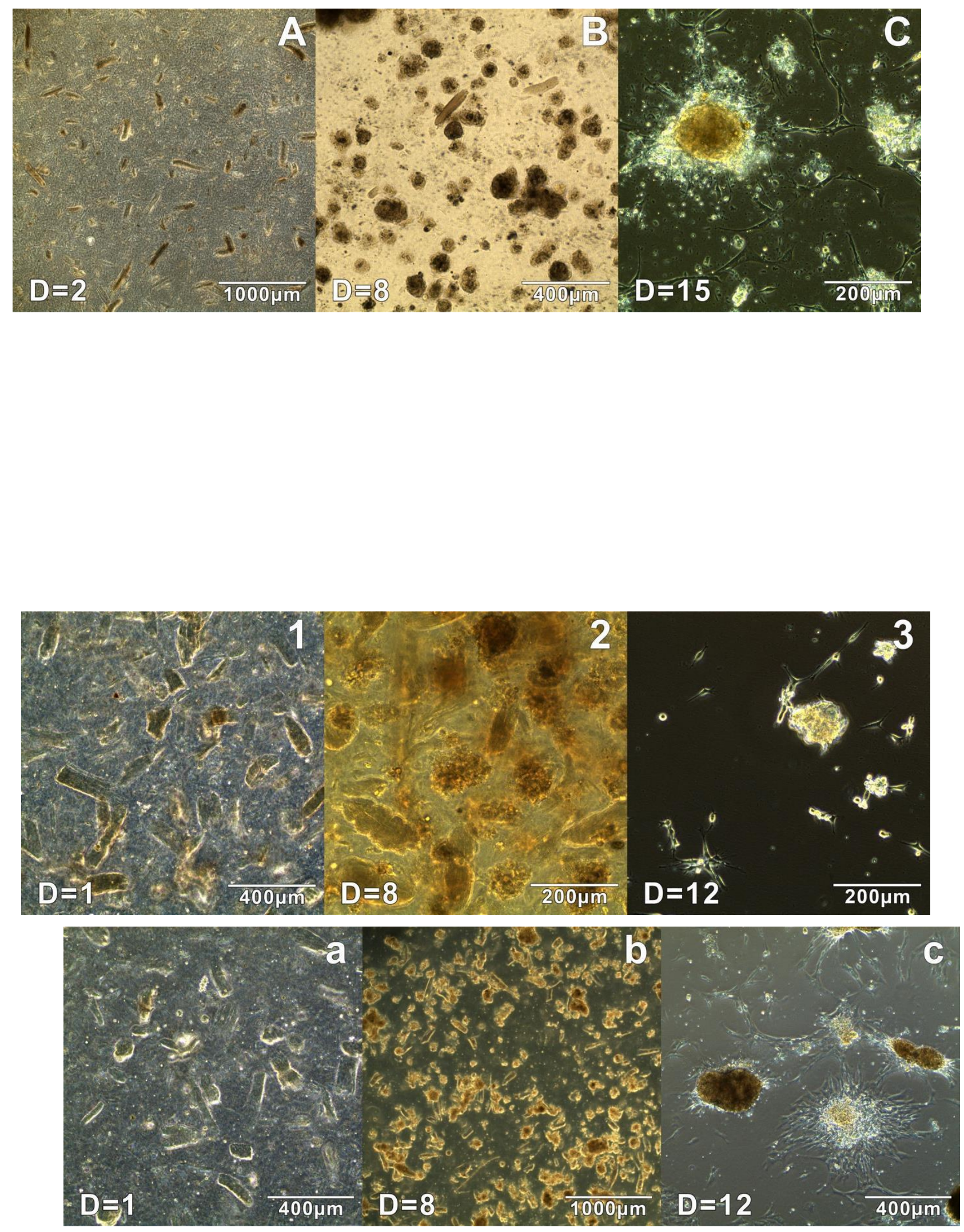

Figure 10. Trend in the Development of Adherent Cells from Cell Suspensions Produced by Enzymatic Digestion. Culture 'Enzymatic B': (A) Cell suspension 2 days post-seeding ( $D=2)$, Spheroids begin to form on day 8 (C) Non-adherent cells in supernatant produce spheroids and 
subsequent adherent cells following cultivation. Culture 'Enzymatic 3': (a) Cell suspension 1 day postseeding (b) Spheroids begin form to within the cell suspension on day 8 (c) Non- adherent cells in supernatant produce spheroids and subsequent adherent cells following cultivation, Culture 'Enzymatic 4': (1) Cell suspension 1 day post-seeding (2) Spheroids begin to form within the cell suspension on day 8 (3) Adherent cells present in original flask, following removal of non-adherent supernatant and cultivation with cell media including $1 \%$ amphotericin B.

\subsection{LIVE/DEAD Staining Assay}

Results from live/dead staining assays using calcein-AM and ethidium homodimer-1 stains indicate that enzymatic and mechanical dissociation methods both display capacity to produce healthy cultures of adherent cells from samples of mammalian tissue (Figure 11). Furthermore, those cultures of adherent cells remain healthy, following repeated splitting and re-seeding.

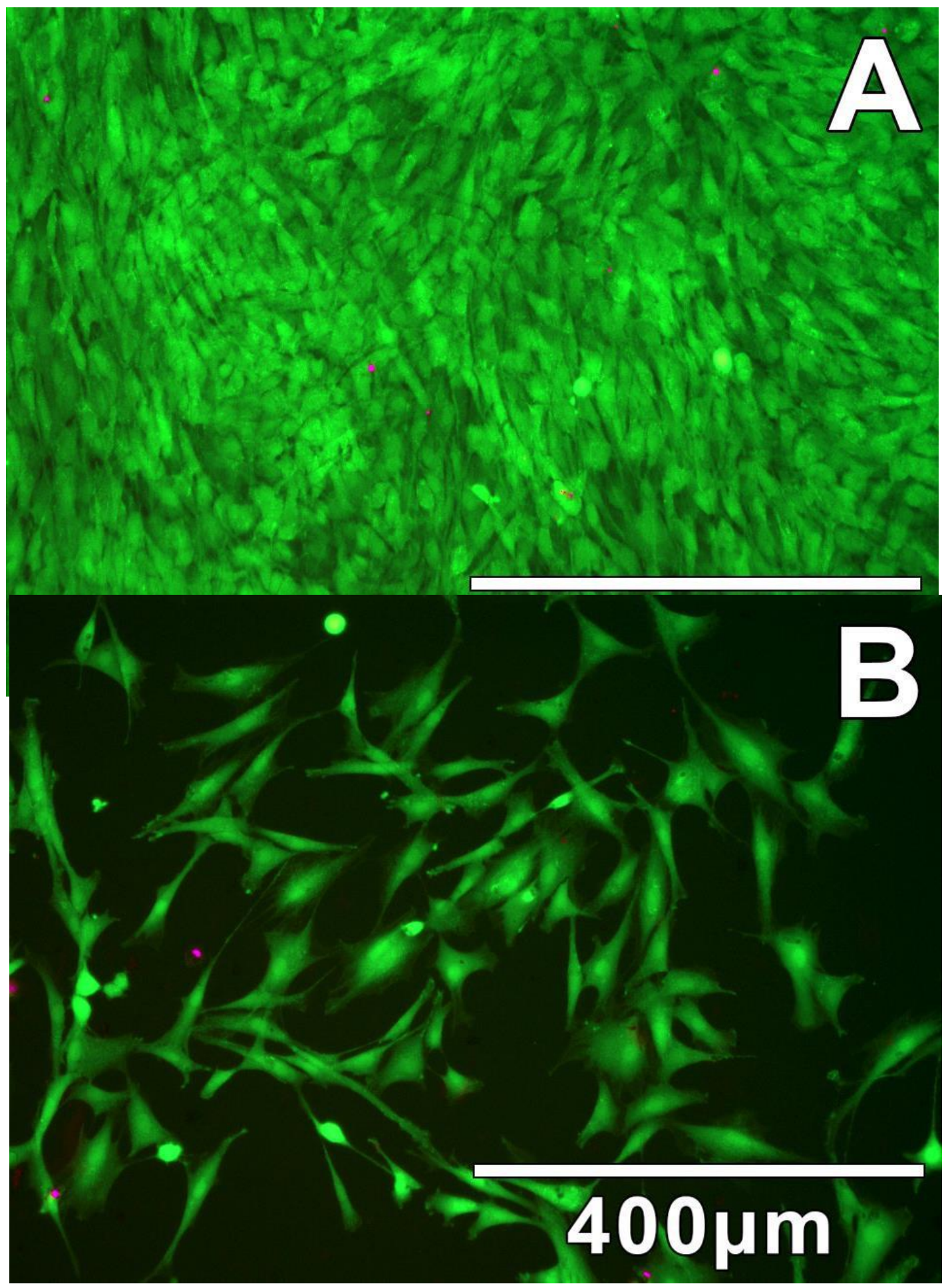


Figure 11. Results from LIVE/DEAD Staining Assays Indicate Both Mechanical and Enzymatic Dissociation Methods Produce Cultures of Healthy Adherent Cells. (A) Densely populated cultures of adherent cells isolated via enzymatic digestion; (B) More sparsely populated cultures of adherent cells isolated via mechanical digestion

\subsection{DAPI/Phalloidin Staining Assay:}

Images of cells stained with DAPI and phalloidin (Figure 12) were taken to gauge the morphology of adherent cells produced from both mechanical and enzymatic dissociation experiments. Staining with phalloidin and counter staining with DAPI allowed for clear identification of filamentous actin structures and nuclei of the cultivated adherent cells. Originally seeded at density of approximately $6.05 \times 10^{4}$ cells per well, enzymatically isolated cells proliferated rapidly over the three days they were in culture to form the dense sheet of cells seen in image A, Figure 12. Due to the slow proliferation rate of adherent cells gained from mechanical dissociation, the entire population of cells isolated from the successful "Mechanical 2" culture and supernatant culture were pooled and seeded into 20 wells of a 24-well plate (Figure 12, B). Those cells isolated using mechanical dissociation have not proliferated to the density as seen in image A. Instead, they present as more stellate structures, each cell covering a far increased area compared to those in image A.

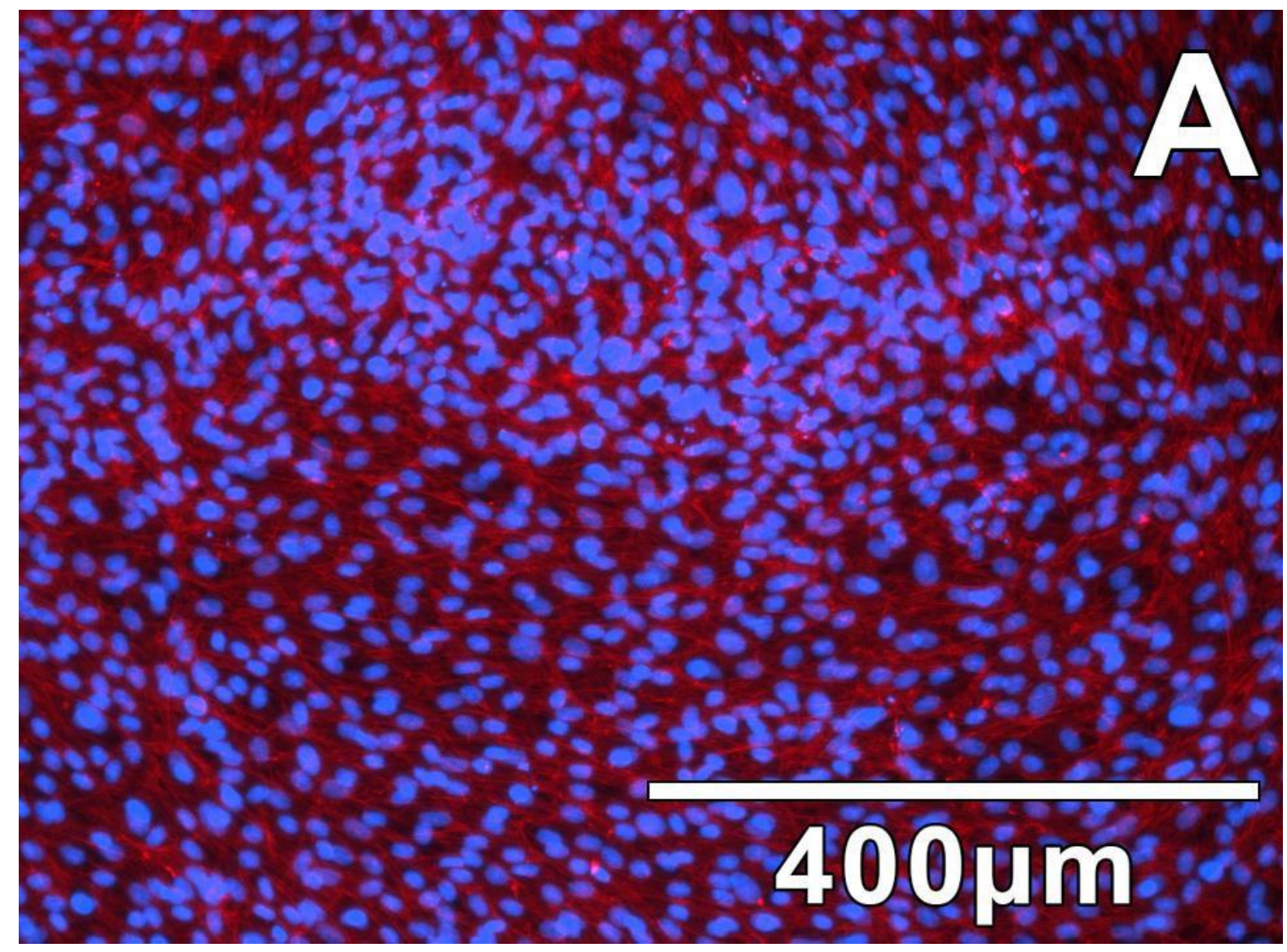




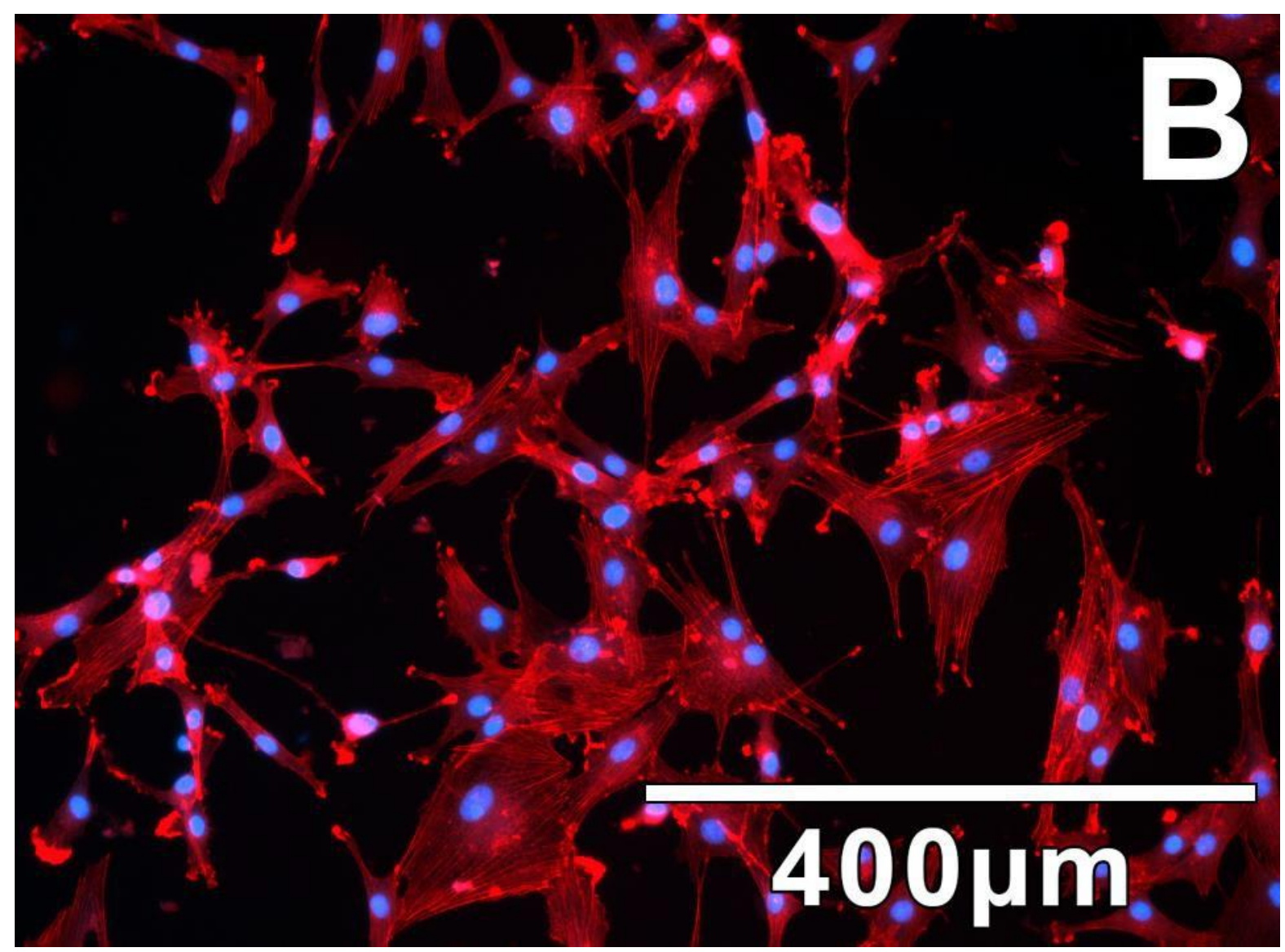

Figure 12. DAPI/Phalloidin staining clearly shows the morphology and density of adherent cells isolated by enzymatic. (A) and mechanical (B) dissociation methods.

\section{Discussion:}

The limitations of currently available treatments for periodontitis lie with the difficulty surrounding regeneration of the complex array of tissues that constitute the periodontium ${ }^{36}$. Hence, attention has turned to stem cell therapies, thanks to their abilities to differentiate into a wide variety of cell types, including those bone, ligament and cementum cells which form the supportive elements of the healthy periodontium ${ }^{13}$.

Varying mechanical methods have been proposed over recent years, each aiming to produce comparable cell suspensions to those gained from tried and tested enzymatic protocols ${ }^{37,33}$. Development of these mechanical methods has been driven by the desire to eliminate enzymatic requirement for both health and economic reasons ${ }^{32}$. The possibility for eliminating the necessity of overnight incubation with expensive enzymes acts as a considerable financial and time saving incentive. For example, the enzymatic digestion protocol used in this study required tissue samples to be exposed to enzymes for a total of 25.5 hours, whereas mechanical dissociation of a single tissue sample takes less than half-an-hour.

In this study, skeletal muscle-derived cell suspensions modeling NCSCs gained from novel mechanical mincing and enzymatic digestion protocols were compared for the first time. The results show how spheroids and adherent cells; similar in morphology to neurospheres and resultant NC-SCs isolated from heterogeneous suspensions of NCCs ${ }^{17,25}$, can be derived from samples of mammalian skeletal muscle treated with both mechanical and enzymatic techniques.

Within this proof-of-concept study, we used multiple state-of-the-art methods to test the structural and visual properties of skeletal muscle-derived cell suspensions modeling NCSCs. 
The handling and preparation of skeletal muscle-derived cells was performed analogous to the preparation of oral-derived NCSCs as detailed in publications of our research group $25-27,29,30$.

Before addressing the hypothesis and research question of this project; data from this report and similar research must be considered to assess whether mechanical dissociation is a viable alternative to enzymatic digestion for the isolation of therapeutic stem cells. Firstly, analysis of cell suspensions immediately following mechanical or enzymatic dissociation was carried out using the Countess Automated Cytometer. This assessment highlighted samples treated with mechanical dissociation as producing an extremely significant increase in liberated living cell populations, compared to those samples treated with enzymatic digestion. Further interpretation of these results revealed, on average, mechanical dissociation produced living cell populations 26.8 times those produced by enzymatic protocols (Table 1).

However, despite indications from similar research suggesting non-enzymatic dissociation yields 2.7-times the number of mesenchymal stem cells compared to collagenase-based dissociation ${ }^{38}$, the living cell populations recorded using automated cytometry from this project proved inconsistent following microscopy and cell culture results.

Increased populations of living cells did not correlate with an increase in successful cell cultures. Only $8.3 \%$ of mechanical cultures produced spheroids and subsequent adherent cells, whereas $44.4 \%$ of tissue samples treated with enzyme digestion produced cultures of adherent cells, despite equal masses of starting material (see Figure 3) and culture conditions. Whilst tissue samples treated with enzymatic digestion produced cell suspensions containing larger fragments of muscle tissue, those cell suspensions treated with mechanical dissociation consisted of significantly finer tissue fragments.

Following dissociation, successful cell cultures seeded with standard cell medium $(20 \%$ Foetal Bovine Serum, 1\% L-Glutamine, 1\% Penicillin-Streptomycin, 78\% Dulbecco's Modified Eagle's Medium - High Glucose, $0.00005 \%$ FGF) began to form spheroids and subsequent adherent cells. Large numbers of spheroids appeared in enzymatic dissociation cultures 6-8 days after seeding cell suspension (see A and B, Fig. 8; and 2, Fig. 9). In comparison, the only successful mechanical dissociation culture produced fewer numbers of spheroid structures 12 days following seeding; identified within the tissue debris caused by mechanical dissociation (A, Fig. 8).

The formation of spheroids and subsequent migration of adherent cells out of these spheroids is mirrored in the formation of neurospheres as seen in studies focusing on NC-SCs isolated from the palate following culture with FGF enriched medium ${ }^{27,25}$. Additionally, research focusing on the enzymatic isolation of multipotent stem cells from PDL documented spheroids production over a similar 7-day course from cell suspensions ${ }^{31}$. However, unlike the studies mentioned above, spheroids cultured in this project were not cultivated in serum-free conditions.

A potential of obtaining cell cultures with neural crest resemblance (neural crest-derived stem cells [NCSCs]) from dental-related tissues, has been discussed in the literature. However, most reports include the use of serum-rich conditions and do not describe the potential for periodontal regeneration, slowing translation to the clinic. Therefore, we aimed to culture and characterize skeletal muscle-derived cell suspensions modeling NCSCs and evaluate their ability to differentiate into periodontal-like cells. Cultures were established from a varied cohort of rat tissue samples and grown, as monolayers, serum-free, and under sphere-aggregation conditions to induce and identify a NCSC-like phenotype. We have characterized oral-derived NCSC cultures from different tissue sources by immunocytochemistry and reverse transcription quantitative polymerase chain reaction in our earlier publications $25-27,29,30$. Here, we tried to handle and preparate skeletal muscle-derived cells performed analogous to the preparation of oral-derived NCSCs. Indeed, skeletal muscle-derived monolayer cultures expressed stem-related markers as shown by Mellow et al 201935 and by Michell et al 201928. Our results describe the establishment of skeletal muscle-derived monolayer culture in serum-free medium modeling NCSC that differentiate into periodontal-like cells, as well as an important effect of serum free media in enhancing the cell phenotype and differentiation comparable to oral-derived NCSCs. 
Additionally, research papers investigating multipotent cells present within the adipose tissue of mice isolated and cultured mesenchymal surface antigen-positive/CD271-positive adherent cells in similar culture media as used in this study ${ }^{39,40}$. Those isolated adherent mesenchymal cells exhibit similar morphology and proliferation rates to adherent cells isolated via both enzymatic and mechanical process in this project. Despite this indicative evidence, this is not sufficient to classify these adherent cells as stem cells. There are three sets of criteria that cells must fulfil to classify as mesenchymal stem cells. Designed by the Mesenchymal and Tissue Stem Cell Committee, these criteria have been implemented in order to standardize classification of human mesenchymal stem cells between studies ${ }^{41,42}$. Cell cultures isolated from this project using mechanical and enzymatic protocols already fulfil the first standard for classification, as cells have shown a preference for adhering to the surface of plastic culture flasks under standard culture conditions. However, further assessment is required into specific expression of surface antigens and the potential for cells to display multipotent differentiation ${ }^{41} .95 \%$ of the suspected mesenchymal stem cells must show expression of surface antigens including CD105, CD 90 and CD73 ${ }^{41}$. Furthermore, $\leq 2 \%$ of cells should positively express antigens CD45, CD34, CD14/CD11b, CD79-alpha/CD19, or HLA-DR ${ }^{41}$. Finally, multipotent differentiation into adipocytes, chondroblasts and osteoblasts must be displayed invitro, under the standard conditions for differentiation ${ }^{41}$.

Alternatively, identification of mesenchymal stem cells based on positive expression of cell surface antigen CD271 has been shown as an effective method of classification, both immediately after isolation and following cell culture ${ }^{42}$. Previous research has proven positive screening for antigen CD271 using CD271 microbeads together with MACS is an effective method for the isolation of mesenchymal stem cells from samples of human adipose tissue ${ }^{43}$.

Development of a novel cleaning procedure was required to facilitate the continued use of the single-use sterile Rigenera Cons mincing apparatus. The enzyme activated detergent Tergazyme was utilized as the main component of the washing protocol. Given the enzymatic activity of this detergent, a cytotoxicity assessment was required to assess suitability with this project. Fibroblasts compared against a control group of an equal concentration were passed through the washed Rigenera Cons mincer and seeded at the same concentration. The resultant cell culture showed no difference in proliferation or cell density in comparison to the control group. Therefore, this novel cleaning procedure proved efficacious at facilitating the cleaning and reuse of the required mincing apparatus, without impacting cell proliferation or survival.

Fluorescent microscopy represented the final assays conducted during this project. The results from live/dead staining using fluorescent markers calcein-AM and ethidium homodimer-1 further display how the adherent cells cultivated from cell suspensions produced by both mechanical and enzymatic cultures were healthy and proliferative.

DAPI/Phalloidin staining revealed additional morphological information about adherent cells isolated from mechanically and enzymatically produced cell suspensions. Despite differences in density of the imaged cells, morphology of both enzymatic and mechanical isolated adherent cells showed similarities to actin-stained examples of undifferentiated human MSCs from previous studies $^{44}$. Furthermore, these stained cells showed similar characteristics to those adherent NC-SCs isolated from ovine palate, imaged with nuclear stain DAPI and the neural crest marker Nestin ${ }^{25}$.

\subsection{Future Directions}

Stem cells continue to hold an exciting potential for the most complete treatment of periodontitis, with MSCs and NC-SCs remaining a focus in this field of research. Advancements are being made towards the culture of stem cells in xeno-free conditions, with use of reagents including Gentle Cell Dissociation Reagent proving useful in studies surrounding human pluripotent stem cells ${ }^{45,46}$. The ease of harvest with minimal donor morbidity, and plentiful access, makes palatal tissue a convenient source for autologous NC cell-based therapies for regenerative periodontal purposes. Optimization of these methods has the potential to offer unprecedented opportunities to further bring effective regenerative therapies at the periodontal surgery in a widely variable applications in oral wound healing, and periodontal plastic-reconstructive fields. At this point in time, the limited 
characterization of the processed material and the inconsistent methods to determine the effect of NC cell transplant represent a limitation for the enormous therapeutic potential of oral-derived neural crest-derived stem cells in a plethora of regenerative applications. Therefore, increased efforts to achieve optimized NCSCs isolation yield and more standardized methods for palatal tissue manipulation for clinical purposes and analysis of grafting are needed.

\section{Conclusion}

Cells with characteristics of putative mesenchymal stem cells were found in regenerating periodontal tissues, implying their involvement in periodontal regeneration. Although periodontalderived neural-crest-derived stem cells have been shown to possess a wide therapeutic range in vivo, there is still no standard protocol with uniform parameters for the isolation and also unclear aspects about the identity of cells isolated from periodontal and/or from palatal tissues. The formation of spheroids and subsequent migration of adherent cells out of these spheroids is mirrored in the formation of neurospheres as seen in studies focusing on NC-SCs isolated from the palate following culture with FGF enriched medium ${ }^{25,30}$. Publication of study outcomes, comparative studies as well as standardization of cell products will allow the field to bring further effective therapy to the clinics. Mechanical dissociation has proven a viable non-enzymatic method of producing cellular suspensions from skeletal muscle, capable of forming adherent cells; the first classification required for identification as stem cells. Furthermore, mechanical dissociation also produced cell suspensions containing considerably higher populations of living cells compared to enzymatic digestion. Rat muscle tissue has proven capable of producing large number of spheroids following enzymatic digestion protocols, with similar proliferation and migration as displayed in PDL-SCs ${ }^{31}$ and NC$\mathrm{SCs}^{27,25}$. This data further reinforce reports of skeletal muscle containing a variety of cells displaying mesenchymal stem cell characteristics ${ }^{47}$. In order to classify isolated adherent cells from this study, colonies should be tested for positive presentation of stem cell surface antigens CD105, CD90 and CD73. Furthermore, assessment of multipotent differentiation into adipocytes, chondroblasts and osteoblasts under standard conditions would confirm stemness of isolated adherent cells ${ }^{41}$. Alternatively, availability of availability of CD271 microbeads used in conjunction with MACS would facilitate identification of cells within the cell suspension. Considering the morphological similarity of spheroids and adherent cells to neurospheres and NC-SCs, testing adherent cells for NC-SC markers p75 (CD271), Nestin and Sox2 would also be appropriate ${ }^{27}$. Finally, the therapeutic suitability of isolated adherent cells could be assessed using a suitable animal model. Moreover, a necessary condition for further clinical translation is represented by standardization of the procedures as well as of the clinical results of the transplantation studies. Publication of study outcomes, comparative studies as well as standardization of cell products will allow the field to bring further effective therapy to the clinics.

Author Contributions: conceptualization, made substantial contributions to conception and design WDG, BG, TF, MAV, AD; methodology, WDG, ND; validation, ND; formal analysis, NE, ND, DI; resources, WDG, BG, $\mathrm{TF}, \mathrm{MAV}$; data curation, ND; visualization, ND; substantially contributed to interpretation of data and analysis $\mathrm{NE}$, DI, KD; writing-original draft preparation KD, WDG; have been involved in drafting the manuscript for important intellectual content; ND, KD, AD, NE, DI, TF, BG; project administration, MAV, WDG, equal work; WDG agreed to be accountable for all aspects of the work in ensuring that questions related to the accuracy or integrity of any part of the work are appropriately investigated and resolved.

Funding: "This research received no external funding".

Conflicts of Interest: "The authors declare no conflict of interest."

Acknowledgments: We thank Mr. Joe Allen for his help with data gathering. The raw data underlying this manuscript have been obtained within a Mpharm dissertation project at the Reading School of Pharmacy.

\section{References:}


1. Papapanou PN, Sanz M, Buduneli N, et al. Periodontitis: Consensus report of workgroup 2 of the 2017 World Workshop on the Classification of Periodontal and Peri-Implant Diseases and Conditions. Journal of periodontology. 2018;89: S173-S182. doi:10.1002/JPER.17-0721

2. Frencken JE, Sharma P, Stenhouse L, Green D, Laverty D, Dietrich T. Global epidemiology of dental caries and severe periodontitis - a comprehensive review. Journal of Clinical Periodontology. 2017;44: S94-S105. doi:10.1111/jcpe.12677

3. Tonetti, M.S., Jepsen, S., Jin, L. and Otomo-Corgel J. Impact of the global burden of periodontal diseases on health, nutrition and wellbeing of mankind: A call for global action. J Clin Periodontol. 2017; 44:456-462.

4. Kinane DF, Stathopoulou PG PP. Periodontal diseases. Nat Rev Dis Primers. 2017;3.

5. Larsson HE, Vehik K, Haller MJ, et al. Growth and risk for islet autoimmunity and progression to type 1 diabetes in early childhood: The environmental determinants of diabetes in the young study. Diabetes. 2016;65(7):19881995. doi:10.2337/db15-1180

6. Kaneda T, Miyauchi M, Takekoshi T, Kitagawa S, Kitagawa M, Shiba H, Kurihara H TT. Characteristics of periodontal ligament subpopulations obtained by sequential enzymatic digestion of rat molar periodontal ligament. Bone. 2006; 38:420-6.

7. Konermann A, Stabenow D, Knolle PA, Held SA, Deschner J, Jäger A. Regulatory role of periodontal ligament fibroblasts for innate immune cell function and differentiation. Innate Immunity. 2012;18(5):745-752. doi:10.1177/1753425912440598

8. Andrukhov O, Hong JS-A, Andrukhova O, Blufstein A, Moritz A, Rausch-Fan X. Response of human periodontal ligament stem cells to IFN- $\gamma$ and TLR-agonists. Scientific Reports. 2017;7(1):12856. doi:10.1038/s41598-017-124807

9. Lin NH, Menicanin D, Mrozik K, Gronthos S, Bartold PM. Putative stem cells in regenerating human periodontium. Journal of Periodontal Research. 2008;43(5):514-523. doi:10.1111/j.1600-0765.2007. 01061 .x

10. Deschner J NM. Regulatory effects of inflammatory and biomechanical signals on regenerative periodontal healing. Int J Oral Maxillofac Implants. 2013;28: e472-e477. doi:10.11607/jomi.te27

11. Miron RJ, Sculean A, Cochran DL, et al. Twenty years of enamel matrix derivative: the past, the present and the future. Journal of Clinical Periodontology. 2016;43(8):668-683. doi:10.1111/jcpe.12546

12. Hynes K, Menicanin D, Gronthos S BP. Clinical utility of stem cells for periodontal regeneration. Periodontol. 2012;59: 203-27. doi:10.1111/j.1600-0757.2012.00443. x

13. Bassir SH, Wisitrasameewong W, Raanan J, et al. Potential for Stem Cell-Based Periodontal Therapy. Journal of Cellular Physiology. 2016;231(1):50-61. doi:10.1002/jcp.25067

14. Seo BM, Miura M, Gronthos S, et al. Investigation of multipotent postnatal stem cells from human periodontal ligament. Lancet. 2004;364(9429):149-155. doi:10.1016/S0140-6736(04)16627-0

15. Achilleos A, Trainor PA. Neural crest stem cells: Discovery, properties and potential for therapy. Cell Research. 2012;22(2):288-304. doi:10.1038/cr.2012.11

16. Sieber-Blum M, Grim M, Hu YF, Szeder V. Pluripotent neural crest stem cells in the adult hair follicle. Developmental Dynamics. 2004;231(2):258-269. doi:10.1002/dvdy.20129

17. Grimm WD, Dannan A, Becher S, et al. The ability of human periodontium-derived stem cells to regenerate periodontal tissues: A preliminary in vivo investigation. International Journal of Periodontics and Restorative Dentistry. Published online 2011. doi:10.11607/prd.00.1020

18. Dupin E, Sommer L. Neural crest progenitors and stem cells: From early development to adulthood. Developmental Biology. 2012;366(1):83-95. doi: 10.1016/j.ydbio.2012.02.035 
19. Chung IH, Yamaza T, Zhao H, Choung PH, Shi S, Chai Y. Stem cell property of postmigratory cranial neural crest cells and their utility in alveolar bone regeneration and tooth development. Stem Cells. 2009;27(4):866-877. doi:10.1002/stem.2

20. Fulco I, Miot S, Haug MD et al. Engineered Autologous Cartilage Tissue for Nasal Reconstruction After Tumour Resection: An Observational First-In-Human Trial. Lancet. 2014; 384:337-346. doi:10.1016/S0140-6736(14)60544-4

21. Hu YF, Gourab K, Wells C, Clewes O, Schmit BD, Sieber-Blum M. Epidermal neural crest stem cell (EPI-NCSC)mediated recovery of sensory function in a mouse model of spinal cord injury. Stem Cell Reviews and Reports. 2010;6(2):186-198. doi:10.1007/s12015-010-9152-3

22. Tabakow P, Raisman G, Fortuna W, et al. Functional regeneration of supraspinal connections in a patient with transected spinal cord following transplantation of bulbar olfactory ensheathing cells with peripheral nerve bridging. Cell Transplantation. 2014;23(12):1631-1655. doi:10.3727/096368914X685131

23. Morrison SJ, White PM, Zock C AD. Prospective identification, isolation by flow cytometry, and in vivo selfrenewal of multipotent mammalian neural crest stem cells. Cell. 1999;96(5):737-749. doi:10.1016/s00928674(00)80583-8

24. Yang $\mathrm{R}, \mathrm{Xu} \mathrm{X}$. Isolation and culture of neural crest stem cells from human hair follicles. Journal of visualized experiments: JoVE. 2013;(74). doi:10.3791/3194

25. Zeuner MT, Didenko NN, Humphries D, et al. Isolation and characterization of neural crest-derived stem cells from adult ovine palatal tissue. Frontiers in Cell and Developmental Biology. 2018;6(APR). doi:10.3389/fcell.2018.00039

26. Grimm WD. Effect of Human Neural Crest-Related Stem Cell Homing (hNCSCs homing) on the Mineralization of Newly Formed Alveolar Bone using an Allogen Bone Substitute. Biomedical Journal of Scientific E Technical Research. 2019;17(2). doi:10.26717/bjstr.2019.17.002987

27. Widera D, Zander C, Heidbreder M, et al. Adult palatum as a novel source of neural crest-related stem cells. Stem Cells. 2009;27(8):1899-1910. doi:10.1002/stem.104

28. Mitchell R, B Mellows, J Sheard, M Antonioli, O Kretz, D Chambers, M-Th Zeuner, JE Tomkins, B Denecke, L Musante, B Joch, F Debacq-Chainiaux, H Holthofer, StRay, T Huber, J Dengjel, PDe Coppi, D Widera' K Patel. Stem Cell Research E Therapy (2019) 10:116 https://doi.org/10.1186/s13287-019-1213-1

29. Grimm WD, Dannan A, Giesenhagen B, et al. Translational research: Palatal-derived ecto-mesenchymal stem cells from human palate: A new hope for alveolar bone and cranio-facial bone reconstruction. International Journal of Stem Cells. Published online 2014. doi:10.15283/ijsc.2014.7.1.23

30. Widera D, Grimm W-D, Moebius JM, et al. Highly efficient neural differentiation of human somatic stem cells, isolated by minimally invasive periodontal surgery. Stem Cells and Development. 2007;16(3). doi:10.1089/scd.2006.0068

31. Techawattanawisal W, Nakahama K, Komaki M, Abe M, Takagi Y MI. Isolation of multipotent stem cells from adult rat periodontal ligament by neurosphere-forming culture system. Biochem Biophys Res Commun. 2007;357(4):917-923. doi: 10.1016/j.bbrc.2007.04.031

32. Bianco de Carvalho L, María Rojano-Delgado A, Luis da Costa Aguiar Alves P, Rafael De Prado B. Differential content of glyphosate and its metabolites in Digitaria insularis biotypes. Communications in Plant Sciences. 3(4):1720. www.complantsci.wordpress.com

33. Oberbauer E, Steffenhagen C, Wurzer C, Gabriel C, Redl H, Wolbank S. Enzymatic and non-enzymatic isolation systems for adipose tissue-derived cells: Current state of the art. Cell Regeneration. 2015;4(1): 4:7. doi:10.1186/s13619-015-0020-0 
34. Bertozzi N, Simonacci F, Grieco MP, Grignaffini E, Raposio E. The biological and clinical basis for the use of adipose-derived stem cells in the field of wound healing. Annals of Medicine and Surgery. 2017; 20:41-48. doi: 10.1016/j.amsu.2017.06.058

35. Mellows B, Mitchell R, Antonioli M, et al. Protein and Molecular Characterization of a Clinically Compliant Amniotic Fluid Stem Cell-Derived Extracellular Vesicle Fraction Capable of Accelerating Muscle Regeneration Through Enhancement of Angiogenesis. Stem Cells and Development. 2017;26(18). doi:10.1089/scd.2017.0089

36. Larsson HE, Vehik K, Haller MJ, et al. Growth and risk for islet autoimmunity and progression to type 1 diabetes in early childhood: The environmental determinants of diabetes in the young study. Diabetes. 2016;65(7):19881995. doi:10.2337/db15-1180

37. Keeve PL, Dittmar T, Gassmann G, Grimm W-D, Niggemann B, Friedmann A. Characterization and analysis of migration patterns of dentospheres derived from periodontal tissue and the palate. Journal of Periodontal Research. 2013;48(3). doi:10.1111/jre.12005

38. Taghizadeh SF, Rezaee R, Davarynejad G et al. Risk assessment of exposure to aflatoxin B1 and ochratoxin A through consumption of different Pistachio (Pistacia vera L.) cultivars collected from four geographical regions of Iran. Environ Toxicol Pharmacol. 2018; 61:61-66. doi: 10.1016/j.etap.2018.05.010

39. Yamamoto K, Sato T, Matsui T, et al. Transcriptional Induction of Mammalian ER Quality Control Proteins Is Mediated by Single or Combined Action of ATF6 $\alpha$ and XBP1. Developmental Cell. 2007;13(3):365-376. doi: 10.1016/j.devcel.2007.07.018

40. Taha MF H v. Isolation, identification and multipotential differentiation of mouse adipose tissue-derived stem cells. Tissue Cell. 2010;42(4):211-216. doi: 10.1016/j.tice.2010.04.003

41. Weyand B, Dominici M, Hass R, Jacobs R, Kasper C. Mesenchymal Stem Cells: Basics and Clinical Application I. http://www.springer.com/series/10

42. Álvarez-Viejo M, Menéndez-Menéndez Y O-HJ. CD271 as a marker to identify mesenchymal stem cells from diverse sources before culture. World J Stem Cells. 2015;7(2): 470-(2):470-476. doi:10.4252/wjsc. V 7.i2.470

43. M.Zanetta, N.Quirici, F.Demarosi, M.C.Tanzi, L.Rimondini SF. Ability of polyurethane foams to support cell proliferation and the differentiation of MSCs into osteoblasts. Acta Biomaterialia. 2009;5(4):1126-1136.

44. Yourek Gregory, Mohammad A. Hussain JJMao. Cytoskeletal Changes of Mesenchymal Stem Cells During Differentiation. ASAIO Journal. Published online 2007:219-228. doi: 10.1097/MAT.0b013e31802deb2d

45. Rodin S, Antonsson L, Niaudet C, et al. Clonal culturing of human embryonic stem cells on laminin-521/Ecadherin matrix in defined and xeno-free environment. Nature Communications. 2014;5. doi:10.1038/ncomms4195

46. Haraguchi Y, Matsuura K, Shimizu T, Yamato M OT. Simple suspension culture system of human iPS cells maintaining their pluripotency for cardiac cell sheet engineering. $J$ Tissue Eng Regen Med. 2015;9(12):1363(12):1363-1375. doi:10.1002/term.1761

47. Jackson RJ, Hellen CUT, Pestova T v. The mechanism of eukaryotic translation initiation and principles of its regulation. Nature Reviews Molecular Cell Biology. 2010;11(2):113-127. doi:10.1038/nrm2838 


\section{Corresponding author:}

Univ.-Prof. Dr. Dr. Wolf-D. Grimm, MSc, Professor of Periodontology, Periodontology, Department of Dentistry, Faculty of Health, Witten/Herdecke University, Germany, Professor (StGMU) of Center for Innovation and Technology Transfer at Stavropol State Medical University, Stavropol, Russian Federation

Mail address

Privat Practice/Praxisteam Hasslinghausen

Univ.-Prof. Dr. Dr. Wolf-D. Grimm, MSc, Professor of Periodontology

Mittelstr. 70

45549 Sprockhövel/Germany

tel: +492339911160

fax: +492339911162

e-mail: prof_wolf.grimm@yahoo.de

Mobil Phone: +49 1731428909 